\title{
EFECTOS DEL TRATADO DE LIBRE COMERCIO ENTRE COLOMBIA Y ESTADOS UNIDOS EN TORNO AL CONTRATO DE FRANQUICIA INTERNACIONAL*
}

\section{EFFECTS OF THE FREE TRADE AGREEMENT BETWEEN COLOMBIA - UNITED STATES IN THE INTERNATIONAL FRANCHISE CONTRACT}

\author{
Shirley Llain-Arenilla** \\ Silvana Insignares-Cera ${ }^{* * *}$ \\ Fecha de recepción: 14 de enero de 2016 \\ Fecha de aceptación: 7 de marzo de 2016 \\ Disponible en linea: 31 de mayo de 2016
}

\section{Para citar este artículo/To cite this article}

\begin{abstract}
Llain-Arenilla, Shirley \& Insignares-Cera, Silvana, Efectos del Tratado de Libre Comercio entre Colombia y Estados Unidos en torno al contrato de franquicia internacional, 132 Vniversitas, 21-58 (2016). http://dx.doi. org/10.11144/Javeriana.vj132.etlc
\end{abstract}

doi: 10.11144/Javeriana.vj132.etlc

\footnotetext{
* El presente artículo es un avance resultado de la ejecución del proyecto de investigación $L a$ interacción del contrato de franquicia internacional en el Tratado de Libre Comercio entre Colombia y Estados Unidos, financiado por la Dirección de Investigación, Desarrollo e Innovación de la Universidad del Norte, en el marco del Observatorio del Comercio Internacional, OBCI, de esta misma institución.

** Master of Laws (LLM) International Law, Stetson University College of Law. Especialista en Derecho Comercial, Universidad Externado de Colombia. Especialista en Contratación Mercantil y abogada, Universidad del Norte. Becaria del XXXVIII Curso de Derecho Internacional, OEA, Brasil. Docente investigadora de la Universidad del Norte. Integrante del grupo de investigación en Derecho y Ciencia Política, Universidad del Norte. Contacto: sllain@uninorte.edu.co

*** Doctora en Derecho y Máster en Gestión de Comercio Internacional, Universidad de Valencia, España. Especialista en Procesos de Integración de la Unión Europea y Latinoamericana, Universidad Carlos III de Madrid. Abogada, Universidad del Norte. Directora del Departamento de Ciencia Política y Relaciones Internacionales, Universidad del Norte. Integrante del grupo de investigación en Derecho y Ciencia Política, Universidad del Norte. Contacto: insignaress@uninorte.edu.co
} 


\section{RESUMEN}

El contrato de franquicia internacional es quizás el contrato de colaboración empresarial más importante en el desarrollo actual de los negocios, pues les permite al franquiciante llevar su modelo de negocio a otros países sin una alta inversión y al franquiciado, realizar una inversión en un negocio, cuya probabilidad de éxito tiene respaldo en la propiedad intelectual licenciada por el franquiciante. Sin embargo, su regulación tanto en el derecho interno como en el derecho del comercio internacional ha sido escasa. Con la entrada en vigencia del Tratado de Libre Comercio (TLC) entre Colombia y Estados Unidos, el 15 de mayo de 2012, se espera un aumento en las oportunidades de negocios y que, en este contexto, el contrato de franquicia se convierta en uno de los instrumentos jurídicos más usuales en las relaciones comerciales internacionales para materializar estas oportunidades. Así, ante la falta de regulación vinculante del contrato de franquicia se hace imprescindible analizar las implicaciones jurídicas que tendrán las reglas fijadas por el TLC entre Colombia y Estados Unidos en este tipo de contrato.

Palabras claves: colaboración empresarial; contrato de franquicia internacional; Tratado de Libre Comercio; régimen jurídico; propiedad intelectual; responsabilidad precontractual 


\section{ABSTRACT}

The international franchise contract is maybe the most important contract of entrepreneurial collaboration in the development of the present business world, because it allows franchisors to bring their models of business to other countries without a high investment, and on the other hand, it allows franchisees to invest in a business, whose probability of success finds support in the intellectual property licensed by the franchisor. However, its regulation in the domestic legislations, as well as, in the international commercial law has been limited. With the entry in force of the Free Trade Agreement (FTC) between Colombia and the United States, raising business opportunities are expected. Within this context, the franchise contract will become one of the most usual legal instruments in the international commercial relations, in order to materialize those business opportunities. Due to the lack of mandatory regulation of the franchise contract, it is then necessary to analyze the legal implications of this contract against the rules established by the FTC between Colombia and the United States.

Keywords: enterprise collaboration; franchise contract; Free Trade Agreement; intellectual property; responsibility; legal regime

\section{SUMARIO}

Introducción.- I. Aspectos generales del Contrato de Franquicia INTERNACIONAL.- II. IMPACTO DEL TLC EN LOS CONTRATOS DE FRANQUICIA internacional en Colombia.- $A$. El contrato de franquicia en Colombia.B. El contrato de franquicia en Estados Unidos.- C. Incidencias del TLC en el contrato de franquicia internacional.- III. PROPUESTA PARA LOGRAR LA CONVERGENCIA DE REGULACIONES DEL CONTRATO DE FRANQUICIA ENTRE Colombia y Estados Unidos.- Conclusiones.- Bibliografía. 


\section{INTRODUCCIÓN}

El contrato de franquicia internacional, como sistema de comercialización, está en constante expansión y se ha convertido en uno de los contratos de colaboración empresarial más utilizados en el escenario de los negocios internacionales contemporáneos. Franquicias como McDonald's, Burger King, Zara, Body Shop, entre otras, son ejemplos del crecimiento de esta figura en el mundo. Tal crecimiento puede obedecer a que, como señala Osvaldo J. MARzorATI, esta figura permite duplicar la comercialización de un producto o servicio'.

Desde el punto de vista conceptual, el contrato de franquicia le permite a un empresario, denominado franquiciador o franquiciante, poner a disposición de otro empresario, denominado franquiciado, la posibilidad de explotar en un determinado territorio una "concepción global de empresa" o la posibilidad de producir y/o comercializar los productos o servicios del primero, por lo cual recibe una contraprestación económica ${ }^{2}$. Así, la franquicia se considera “...un contrato entre dos partes, por el cual el franquiciante le permite al franquiciado comercializar cierto producto o servicio, bajo marca y símbolo, contra el pago de un derecho de entrada o de regalías, o de ambas cosas..."3.

Ahora bien, con la entrada en vigencia del Tratado de Libre Comercio (TLC) suscrito entre Estados Unidos y Colombia ${ }^{4}$, se espera un incremento de franquicias internacionales entre ambos Estados, situación que producirá efectos positivos y negativos que todavía están por estudiarse y que de alguna manera también han sido previstos por otros Estados en TLC similares. Un ejemplo de esta situación aparece en el Tratado de Libre Comercio entre Chile y Estados Unidos ${ }^{5}$, pues un estudio sobre los desafíos competiti-

1 Osvaldo J. Marzorati, Sistemas de distribución comercial, 228 (3 $3^{\mathrm{a}}$ ed., Astrea, Buenos Aires, 2011).

2 Alfonso Ortega-Giménez, El contrato de franquicia internacional: hacia la idea global de empresa, 9 (España Exportación e Inversiones, ICEX, Madrid, 2010).

3 Osvaldo J. Marzorati, Sistemas de distribución comercial, 228 (3 ${ }^{\mathrm{a}}$ ed., Astrea, Buenos Aires, 2011).

4 Colombia \& Estados Unidos, Tratado de Libre Comercio (TLC), vigente desde el 15 de mayo de 2012. Disponible en: http://www.tlc.gov.co/publicaciones.php?id=727

5 Chile y Estados Unidos, Tratado de Libre Comercio, vigente desde el 1 de enero de 2004. Disponible en: http://www.wipo.int/edocs/lexdocs/treaties/es/cl-us/trt_cl_us.pdf 
vos para Chile frente a los tratados de libre comercio, señaló que con la firma de este TLC, conforme a las tendencias mundiales, "se multiplicará el otorgamiento de franquicias" sobre todo de las compañías estadounidenses hacia Chile y acota que este puede impactar negativamente los pequeños comercios locales ${ }^{6}$.

Por otro lado, desde una perspectiva jurídica, el aumento de relaciones de franquicia derivado de la suscripción del TLC, obliga a plantear un estudio sobre su regulación y sobre los potenciales problemas jurídicos, teniendo en cuenta que el contrato de franquicia internacional hace parte de los denominados contratos atípicos dada la poca (y en algunos casos, inexistente) regulación tanto en el derecho interno como en el derecho comercial internacional ${ }^{7}$.

Nuestro objetivo es analizar la convergencia derivada de las regulaciones del contrato de franquicia internacional, tanto en Colombia como en Estados Unidos, y las obligaciones especiales contenidas en el TLC suscrito entre ambas naciones. Para ello, presentaremos las generalidades del contrato de franquicia internacional, seguido de un análisis de los potenciales efectos del TLC en los contratos de franquicia internacional que tienen ejecución en Colombia; y, por último, plantearemos una propuesta para lograr una aproximación de regulaciones del contrato de franquicia entre Colombia y Estados Unidos.

6 Alicia Gariazzo, Tratados de libre comercio y desafios competitivos para Chile: la extensión de la ISO 9000, 60 (Serie Desarrollo Productivo, 147, Comisión Económica para América Latina y el Caribe, CEPAL, Santiago de Chile, 2004). Disponible en: http://archivo.cepal.org/ pdfs/2004/S04143.pdf. De igual forma, en el caso de Perú, al advertir las oportunidades de negocios que vendrían con la firma del TLC con Estados Unidos, con el apoyo de la Agencia de Estados Unidos para el Desarrollo Internacional (United States Agency for International Development, USAID), realizó un estudio sobre los aspectos sustantivos y normativos del negocio de franquicia en ese país. Luis Kiser-Rodríguez, Franquicias, la elaboración de una idea de negocio, en base a la oportunidad detectada (Nathan Associates, Lima, Perú, 2009). Disponible en: http://www.crecemype.pe/portal/images/stories/files/FRANQUICIAS.pdf. Perú \& Estados Unidos, Tratado de Libre Comercio (TLC), vigente desde el 1 de febrero de 2009. Disponible en: http://www.acuerdoscomerciales.gob.pe/index.php?option=com_conte nt\&view $=$ category\&layout $=$ blog\&id $=57 \&$ Itemid $=80$

7 En el ámbito internacional no hay tratados en la materia, pero sí hay leyes modelo, contratos tipos y principios en el derecho comercial internacional. 


\section{ASPECTOS GENERALES DEL CONTRATO DE FRANGUICIA INTERNACIONAL}

El origen histórico de la franquicia de producto moderna, y de la franquicia en general, se remonta a 1851 cuando un hombre buscó la forma de poder vender su máquina de coser más allá de lo que le permitía su capacidad económica y así salir de su precaria situación que, por un lado, le impedía abrir tiendas y, por otro, no podía obtener suficiente dinero para surtir máquinas de coser a consignación a lo largo de Estados Unidos. Así fue como Albert Singer creó la primera red de franquiciatarios de la historia, al decidir vender sus máquinas de coser a sus propios vendedores para que estos las revendieran a los consumidores a un precio más alto $^{8}$. En esta línea, General Motors desarrolló este mismo sistema de distribución comercial ${ }^{9}$ que es actualmente fuente de cientos de negocios alrededor del mundo ${ }^{10}$.

Ahora bien, la regulación del contrato de franquicia internacional es casi tan atípica como su regulación en el mercado nacional. En el derecho comercial internacional, hay instrumentos de soft law, como la Ley Modelo sobre la divulgación de la información en materia de franquicia, creada por el Instituto Internacional para la Unificación del Derecho Privado, UNIDROIT ${ }^{11}$, que intentan fijar el concepto, las características y los elementos esenciales de este contrato, que giran en torno al licenciamiento del know-how que

8 Rodrigo Alberto Plazas-Estepa, El know-how dentro de los contratos de franquicia en Colombia, 10 Revista Republicana, 67-79 (2011). Disponible en: http://revista.urepublicana. edu.co/wp-content/uploads/2012/07/El-know $\%$ E2\%80\%93howdentro-de-los-contratos-defranquicia-en-Colombia.pdf. Aunque el origen de la franquicia se ubica en la edad media, autores como Osvaldo Marzorati señalan que la franquicia comercial tuvo inicio en el siglo XIX en Estados Unidos. Osvaldo J. Marzorati, Sistemas de distribución comercial, 225 (3 ${ }^{\mathrm{a}}$ ed., Astrea, Buenos Aires, 2011).

9 Lorena Castellanos-Peñafiel, El contrato de franquicia en el comercio internacional, 5 Foro, Revista de Derecho, 105-125 (2006). Disponible en: http://repositorio.uasb.edu.ec/ bitstream/10644/1717/1/RF-05-TC-Castellanos.pdf

10 De acuerdo con la European Franchise Federation, EFF, a agosto de 2012, había 20.655 marcas objeto de franquicias en el mundo, sin contar los países europeos. En: http://www. eff-franchise.com/Data/PUBLICATION $\% 202012 \% 20 \mathrm{EFF} \% 20 \mathrm{FRANCHISE} \% 20 \mathrm{REPORT}$. pdf. Esta misma organización estableció en sus estadísticas que a 2014 había un número de 13.627 marcas objeto de franquicia en 21 países europeos. En: http:/www.eff-franchise.com/ Data/FRANCHISE \%20STATISTICS\%20-\%20EUROPE \%20-\%20source-EFF.pdf

11 Instituto Internacional para la Unificación del Derecho Privado, UNIDROIT, Ley Modelo sobre la divulgación de la información en materia de franquicia, Roma, 2004. Disponible en: http://www.unidroit.org/spanish/modellaws/2002franchise/2002modellaw-s.PDF 
realiza el franquiciador al franquiciado y que incluye un control significativo y continuo del primero, asociado a su marca, nombre comercial o logotipo.

En ese orden de ideas, el contrato de franquicia internacional tiene entre sus elementos esenciales: el licenciamiento de propiedad industrial, la transmisión del know how, la prestación de asistencia técnica por parte del franquiciante y el pago de una regalía como contraprestación. Otros autores incluyen también el territorio, la no competencia y/o las posibilidades de subfranquiciar, la confidencialidad y el plazo o duración del contrato ${ }^{12}$.

Por otro lado, el contrato de franquicia se caracteriza por ser consensual, bilateral, oneroso, y principal; puede ser verbal o escrito; no requiere ninguna formalidad para su perfeccionamiento distinta al acuerdo de las partes; genera obligaciones recíprocas; ambos contratantes obtienen una contraprestación con la ejecución del contrato y el contrato subsiste por sí mismo. De igual forma, se le ha endilgado el carácter de contrato de adhesión porque "... sus cláusulas no son libremente negociables o modificables por el franquiciatario" 13 y de contrato de tracto sucesivo en la medida en que se agota en un determinado período y no en un solo acto. Autores como LoRena CASTEllanos-Peñafiel han señalado como otras características de este contrato las de ser un contrato de cooperación e intuitu person $a^{14}$. Se trata de un contrato de colaboración, y sus obligaciones son de resultados.

12 Alfonso Ortega-Giménez, El contrato de franquicia internacional: hacia la idea global de empresa, 10-11 (España Exportación e Inversiones, ICEX, Madrid, 2010). LoREnA CastellanosPEÑAfIEL considera que licenciamiento de la "marca y la comunicación del know how son elementos imprescindibles en todo contrato de franquicia", además de otros elementos propios de otros tipos contractuales "tales como la licencia de derechos sobre bienes inmateriales, la asistencia técnica, la concesión, el suministro y el arrendamiento — por citar algunos ejemplos - y, por tanto, combina las obligaciones inherentes a ellos...". LORENA CASTELLANOSPEÑAfIel, El contrato de franquicia en el comercio internacional, 5 Foro, Revista de Derecho, 105-125, 110-111 (2006). Disponible en: http://repositorio.uasb.edu.ec/bitstream/10644/1717/1/ RF-05-TC-Castellanos.pdf

13 Miguel Fernando Londoño-Álvarez, El contrato de franquicia internacional en Colombia, 26 Foro del Jurista, 137-146 (2005). Disponible en: http://www.camaramedellin.com.co/site/ Portals/0/Documentos/Biblioteca/herramientas/libro-como-exportar-en-colombia-derechodistribucion-comercial.pdf

14 Lorena Castellanos-Peñafiel, El contrato de franquicia en el comercio internacional, 5 Foro, Revista de Derecho, 105-125 (2006). Disponible en: http://repositorio.uasb.edu.ec/ bitstream/10644/1717/1/RF-05-TC-Castellanos.pdf. FABIÁN LóPEZ-GuZMÁn, El contrato de franquicia internacional. Un modelo estratégico empresarial, 27-30 (Ediciones Jurídicas Gustavo Ibáñez, Bogotá, 2005). Osvaldo J. Marzorati, Sistemas de distribución comercial, 169-170 (3ª ed., Astrea, Buenos Aires, 2011). 
Acerca del contrato de franquicia internacional, el tema de su naturaleza jurídica representa el punto de mayor discusión. Por ejemplo, para el Departamento de Comercio de Estados Unidos, la franquicia comercial no es más que una forma de licencia, por la cual el propietario o titular (franquiciante) de un producto, servicio o método lleva a cabo su distribución por medio de revendedores afiliados (franquiciados) ${ }^{15}$, mientras que para otros autores como William A. Gregory y Thomas R. Hurst, la franquicia es un tipo de contrato de distribución por el cual bienes y servicios se llevan al mercado, y un negocio independiente actúa como el representante de otro negocio: el franquiciado realiza el negocio de la misma manera y bajo el control del franquiciante ${ }^{16}$ (traducción libre).

\section{IMPACTO DEL TLC EN LOS CONTRATOS DE FRANQUICIA INTERNACIONAL EN COLOMBIA}

El TLC Colombia-Estados Unidos producirá efectos importantes en diversas áreas del derecho y de la vida de los negocios. Uno de esos efectos se verá representado en la forma de estructurar negocios jurídicos que faciliten el intercambio de bienes y servicios, o que posibiliten la inversión extranjera. El TLC impactará los contratos de franquicia, en la medida en que - como resultado de las obligaciones adquiridas en virtud del TLC - el otorgamiento de franquicias y la entrada de inversionistas extranjeros para expandir sus operaciones comerciales por esta figura se multiplicarán.

15 Osvaldo J. Marzorati, Sistemas de distribución comercial, 230 ( $3^{\mathrm{a}}$ ed., Astrea, Buenos Aires, 2011).

16 William A. Gregory \& Thomas R. Hurst, Unincorporated Business Associations (3 ed., Thomson, West Academic Publishing, Saint Paul, Minnesota, 2006). Manuel Guerrero-Gaitán señala que en Estados Unidos se ha debatido la relación entre el contrato de franquicia y la distribución en casos como Joseph James, Darrell Woods and Saint Louis Appliance Parts Inc. v. Whirlpool Corp. En este caso, la Corte estableció el control significativo sobre las operaciones de explotación comercial como elemento diferenciador entre el contrato de franquicia y el contrato de distribución. MANUel Guerrero-Gattán, Los contratos de transferencia internacional de tecnología: América Latina, Estados Unidos y la Unión Europea, 85-86 (Editorial Universidad Externado de Colombia, Bogotá, 2014). Shirley Llain-Arenilla, El contrato de franquicia internacional: aspectos generales, en Contrato de franquicia internacional en el marco del TLC Colombia-USA, perspectivas jurídicas y económicas, 1-26, 10 (Silvana Insignares-Cera, ed., Universidad del Norte, ECOE Ediciones, Bogotá, 2015). United States District Court for the Eastern District of Missouri, Joseph James, Darrell Woods and Saint Louis Appliance Parts Inc. v. Whirlpool Corp., 806 F. Supp. 835 (Eastern District Missouri 1992), October 26, 1992. Disponible en: http://law.justia.com/cases/federal/district-courts/FSupp/806/835/1747761/ 


\section{A. El contrato de franquicia en Colombia}

En la legislación colombiana, se presentan distintos tipos de elementos relacionados con las partes, el objeto y la clasificación legal del contrato de franquicia. En este sentido, las partes, como elemento del contrato, están determinadas por dos extremos: el franquiciante y el franquiciado. Ellos se obligan al cumplimiento recíproco de obligaciones; de allí se desprende su carácter bilateral. Así pues, el contrato de franquicia es el acuerdo de voluntades en el cual una corporación, el franquiciante, que ha venido desarrollando un método o una fórmula para la fabricación y/o venta de un producto o servicio, extiende a otras firmas, los franquiciados, el derecho a proseguir con este negocio sujeto a ciertos controles y restricciones ${ }^{17}$.

Conforme a ello, el contrato de franquicia en Colombia tiene una naturaleza atípica. Sin embargo, se identifican los siguientes elementos claves: (i) es bilateral; (ii) oneroso; (iii) conmutativo; (iv) consensual; (v) de adhesión, porque sus cláusulas en su mayoría no son negociables; (vi) de tracto sucesivo; y (vii) con obligaciones de resultados, las cuales se derivan de las disposiciones del contrato. En este orden de ideas, los elementos del contrato de franquicia son:

1. Las partes $^{18}$

2. El precio $^{19} \mathrm{y}$

17 Jaime Alberto Arrubla-Paucar, Contratos mercantiles III, 37 (Diké, Medellín, 2006).

18 Las partes están representadas por el franquiciante y el franquiciado; el primero — que recibe el nombre de otorgante, cedente, ofranchisor - es la parte que posee la titularidad y, por tanto, puede transferir o licenciar el uso de los bienes, las marcas, los signos, los distintivos, la tecnología, el modus operandi y las estrategias económicas para la producción y comercialización de los bienes y prestación de servicios; mientras que el franquiciado - tomador, concesionario o franchisee - es un comerciante independiente que, gracias a relación jurídica-contractual que tiene con el franquiciante, puede hacer uso de un cierto grupo de derechos para distribuir bienes o prestar servicios. Pablo José Quintero-Delgado, El contrato de franquicia, 55 (Ediciones Jurídicas Gustavo Ibáñez, Pontificia Universidad Javeriana, Bogotá, 2012).

19 Está representado por dos rubros, que pueden clasificarse como uno general que consiste en el pago global que se produce al momento del perfeccionamiento del contrato y que comprende la asistencia general del franquiciante al franquiciatario, lo cual implica la capacitación básica del negocio, la entrega de los manuales técnicos y operativos, las especificaciones técnicas y comerciales de los locales comerciales que se van a utilizar, la entrega de material publicitario y demás condiciones derivadas de las obligaciones del contrato. Algunos contratos de carácter nacional no incluyen estos aspectos que son considerados necesarios para asegurar la viabilidad del negocio, por lo que algunos sectores ven su no inclusión como desconocimiento de las condiciones mínimas que requiere un contrato de franquicia. La segunda variable del precio está conformada por el canon mensual o regalía (royalty), que se determina teniendo en cuenta las ventas brutas del mes. Miguel Fernando Londoño-Álvarez, El contrato de franquicia internacional en Colombia, 26 Foro del Jurista, 137-146 (2005). Disponible en: http:// www.camaramedellin.com.co/site/Portals/0/Documentos/Biblioteca/herramientas/libro- 


\section{La duración del contrato ${ }^{20}$}

De la misma manera, en atención a la naturaleza atípica del contrato de franquicia en Colombia, se presentan inconvenientes en su implementación debido a las grandes similitudes con los contratos de compraventa, distribución, locación, arrendamiento y agencia comercial, lo cual no implica la absorción de la franquicia por estos contratos, es decir, la franquicia como contrato conserva su autonomía. Esta situación ha sido ampliamente estudiada por las distintas autoridades del Estado colombiano, mediante las cuales se ha intentado realizar una caracterización específica de los elementos que conforman el contrato de franquicia en Colombia.

Así, la Corte Suprema de Justicia, a pesar de sus escasos pronunciamientos sobre el tema, debido a la no concurrencia de las partes a la instancia judicial, ha realizado un análisis de los elementos del contrato, como consta en el caso identificado con el expediente $3939^{21}$, en el que estipuló que la publicidad se considera como un elemento del contrato de franquicia, al señalar que debe realizarse a nombre del franquiciador, como un elemento para adquirir la clientela para el nuevo establecimiento de comercio. Por tanto, cuando se utiliza el nombre del anterior franquiciador y se trabaja con su clientela, se considera un acto de competencia desleal.

Por otra parte, frente a la utilización de la franquicia en los contratos de adhesión, la Sala de Casación Civil de la Corte Suprema de Justicia, en su sentencia del expediente $5905^{22}$, la Corte manifestó la importancia que ha adquirido el contrato de franquicia en las relaciones comerciales colombianas ${ }^{23}$.

como-exportar-en-colombia-derecho-distribucion-comercial.pdf

20 Es el plazo fijado por las partes para la recuperación de la inversión inicial realizada. Generalmente, estos contratos de franquicia internacional oscilan entre 2 y 5 años, tiempo prudente para recuperar la inversión inicial del franquiciado y poder alcanzar los niveles de utilidad proyectados, por las partes. Alfonso ORTEGA-Giménez, El contrato de franquicia internacional: hacia la idea global de empresa, 11 (España Exportación e Inversiones, ICEX, Madrid, 2010).

21 Corte Suprema de Justicia, Sala de Casación Civil y Agraria, sentencia del 12 de septiembre de 1995, expediente 3939, magistrado ponente Nicolás Bechara-Simancas. Disponible en: http://www.notinet.com.co/pedidos/3939.doc

22 Corte Suprema de Justicia, Sala de Casación Civil y Agraria, sentencia del 8 de agosto de 2001, expediente 5905, magistrado ponente Jorge Antonio Castillo-Rugeles.

23 Al respecto, la Corte manifestó: "De otra parte, está claro que en países como el nuestro, donde los grandes sistemas de tarjetas de crédito imperantes se desarrollan bajo la modalidad de la franquicia (franchising), los aceptantes adheridos adquieren prácticamente una doble vinculación contractual: de un lado, con la entidad que materialmente concede la vinculación 
No obstante lo anterior, la jurisdicción arbitral ha sido más activa en cuanto a pronunciamientos sobre el contrato de franquicia, ello debido a la aplicación de las cláusulas arbitrales en este tipo de contratos. Frente a la coexistencia de contratos, en el laudo arbitral Gallo's Comunicaciones E.U. vs. Super 9 Comunicaciones S.A., un Tribunal de Arbitramento, adscrito al Centro de Conciliación y Arbitraje de la Cámara de Comercio de Bogotá, procedió a determinar que el contrato de franquicia en Colombia puede coexistir con otros contratos, como el contrato de arrendamiento, y de agencia mercantil, lo cual no significa que aquel sea absorbido por estos ${ }^{24}$.

Conforme a ello, los tribunales de arbitramento se han permitido identificar los elementos esenciales del contrato de franquicia, para fijar la autonomía del mismo en el ordenamiento jurídico colombiano. El laudo arbitral Supercar Ltda. v. Sociedad de Fabricación de Automotores S.A., Sofasa ${ }^{25}$, estableció en una línea de tiempo, las características básicas de la franquicia como contrato atípico. Así, el Tribunal realizó un estudio comparado teniendo en cuenta la doctrina y jurisprudencia europea sobre los elementos de los contratos de agencia comercial y suministro, y como elemento diferenciador fundamental entre el contrato de agencia mercantil y el de franquicia encontró la autonomía que el franquiciante tiene en este último, frente a la subordinación que el agente le debe al empresario ${ }^{26}$.

y que a la vez otorga las autorizaciones para que se ejecute una determinada transacción comercial y, por otro, con aquella que a la organización del sistema proporciona servicios de control, vigilancia y seguridad".

24 En este sentido, el laudo estableció que: "No se trata de contratos estrictamente principales, puesto que están sometidos en sus efectos a otros actos jurídicos, pero tampoco son accesorios puesto que no tienen la función de garantizar otras obligaciones. En su obra El negocio jurídico, el profesor Francesco Galgano sostiene que existe 'una pluralidad coordinada de contratos, cada uno de los cuales responde a una causa autónoma, aun cuando en conjunto tiendan a la realización de una operación económica unitaria y completa"'. Centro de Arbitramento de la Cámara de Comercio de Bogotá, Gallo's Comunicaciones E.U. vs. Super 9 Comunicaciones S.A., laudo arbitral de 17 de noviembre de 2004. Francesco Galgano, El negocio jurídico (Tirant lo Blanch, Valencia, 1992).

25 Centro de Arbitramento de la Cámara de Comercio de Bogotá, Supercar Ltda. vs. Sociedad de Fabricación de Automotores, Sofasa S. A., laudo arbitral de 31 de marzo de 1998.

26 En cuanto a las diferencias, el tribunal de arbitramento manifestó: "La autora [TERESA PUENTEMuÑoz] señala que existen algunas obligaciones iguales o semejantes en ambos contratos y que la remuneración del concesionario no deja de asemejarse a la comisión del agente comercial. Sin embargo, comenta la jurisprudencia francesa en el sentido de que 'el concesionario compra la mercancía en su nombre propio y a su riesgo y peligro, tanto que su actividad se lleva a cabo en interés del concedente o interés común de ambos. Será un revendedor no un mandatario"”. Centro de Arbitramento de la Cámara de Comercio de Bogotá, Supercar Ltda. vs. Sociedad 
La jurisdicción arbitral se permitió ratificar esta posición en el laudo arbitral de Telemóvil Colombia S.A. vs. Colombia Móvil S. A. $E S P^{27}$, cuando señaló como criterio diferenciador de los contratos de franquicia y agencia comercial, la imposición por parte del productor (franchisor) de todo un plan de mercado al revendedor (franchisee), que incluyen aspectos como la presentación del local, su adecuación y métodos de promoción de ventas, el cual no se exige en el contrato de agencia mercantil.

Aunado a lo anterior, la jurisdicción arbitral se ha encargado de establecer las características propias del contrato de franquicia, con el ánimo de presentar los elementos diferenciadores frente a otros contratos, y de fijar la autonomía del mismo. En este sentido, en el laudo arbitral de Chevron Petroleum Company vs. Marina Fandiño de Rubio y Carlos Guillermo Rubio-Fandiño ${ }^{28}$, el tribunal realizó un análisis sobre el carácter atípico del contrato de franquicia y apuntó que este carácter no impide la individualización del mismo, ni la determinación de las características propias del contrato, las cuales se identifican a pesar de haber suscrito el contrato bajo otra denominación. Este laudo es fundamental para la individualización del contrato de franquicia y para el señalamiento de sus principales características $^{29}{ }^{30}$.

de Fabricación de Automotores, Sofasa S.A., laudo arbitral de 31 de marzo de 1998, que cita a Teresa Puente-Muñoz, El contrato de concesión mercantil (Montecorvo, Madrid, 1976), que cita a Jean Catoni, La rupture du contrat d'agent commercial (Sirey, Paris, 1970).

Y continúa el laudo: “(...) [Álvaro Mendoza-Ramírez] Concluye 'Quizá lo importante no es considerar a la agencia como figura autónoma, sino como relación jurídica abierta a toda una serie de posibilidades subordinadas. Entre ellas, el mandato y el suministro, expresamente correlacionados por el artículo 1330 [Código de Comercio]; el contrato de consignación o estimatorio; y aquellos expresamente asignados a esta charla, es decir, los de franquicia, concesión y licencia de uso, etc.'... Analiza distintas figuras y concluye que la franquicia o el arrendamiento comercial de bienes incorporales y la concesión, pueden revestir el carácter de agencia; solo excluye de esa posibilidad la licencia de uso". Centro de Arbitramento de la Cámara de Comercio de Bogotá, Supercar Ltda. vs. Sociedad de Fabricación de Automotores, Sofasa S. A., laudo arbitral de 31 de marzo de 1998.

27 Centro de Arbitramento de la Cámara de Comercio de Bogotá, Telemóvil Colombia S.A. vs. Colombia Móvil S.A. ESP, laudo arbitral de 3 de mayo de 2007.

28 Centro de Arbitramento de la Cámara de Comercio de Bogotá, Chevron Petroleum Company vs. Mariana Fandiño de Rubio y Carlos Guillermo Rubio-Fandiño, laudo arbitral de 16 de septiembre de 2008.

29 Centro de Arbitramento de la Cámara de Comercio de Bogotá, Tribunal de arbitramento ad-hoc, Megaenlace Net S.A., vs. Telefónica Móviles de Colombia S.A., laudo arbitral de 25 de marzo de 2009, sobre el contrato de agencia comercial, uno de los contratos que presenta similitudes con el contrato de franquicia.

30 En esta oportunidad, el tribunal estipuló: "3.2. El contrato celebrado no es de subarriendo sino de franquicia. Sostiene la convocada que el contrato titulado por las partes no es de 
Finalmente, el tribunal de arbitramento adscrito a la Cámara de Comercio de Bogotá, en el laudo arbitral División Mayor del Fútbol Colombiano, Dimayor, vs. Radio Cadena Nacional S.A., $R C N$ y Caracol Televisión $S . A .^{31}$, realizó una diferenciación entre los contratos de agencia, suministro y arrendamiento, y conceptuó que la marca y el know-how son elementos esenciales del contrato de franquicia ${ }^{32}$.

subarriendo, sino de franquicia. Para el tribunal, la acepción que a los contratos se otorgue no puede superar la que emane de su naturaleza. En el presente caso, y como lo reconoce la propia convocante, el llamado contrato de subarriendo no es propiamente de subarriendo, ya que no emana ni surge como consecuencia de un arriendo previo cedido a la convocada. Respecto a la naturaleza del contrato de franquicia, modalidad de la concesión comercial como la convocada apropiadamente denomina el contrato en estudio, es necesario establecer los elementos fundamentales, los cuales según la Unidroit (citada en su libro El contrato de franquicia internacional, del autor Fabián López-Guzmán, página 172, Editorial Ediciones Jurídicas Gustavo Ibáñez) son: UNIDROIT propone la siguiente definición de franquicia: 'Es una operación de franquicia la operación contractual entre un franquiciante y un franquiciado, en la cual el franquiciante ofrece o es obligado a mantener un interés permanente en el negocio del franquiciado, en aspectos tales como del know-how y la asistencia técnica. El franquiciado opera bajo un nombre comercial conocido, un método y un procedimiento que pertenece, o que es controlado por el franquiciante, $\mathrm{y}$ en el cual el franquiciado ha hecho o hará una inversión sustancial en su propio negocio con sus propios recursos'. De ello, se desprende que en la franquicia es primordial la licencia de uso de una marca, así como la transferencia de un know-how. Pero, fundamentalmente el que la franquicia surge como un vehículo jurídico que permite al franquiciante (quien la otorga) que alguien (el franquiciado) desarrolle la inversión necesaria para expandir los negocios del franquiciador, de tal manera que este último pueda expandirse sin incurrir en los gastos de capital que su crecimiento requiere. Así las cosas, en el presente caso, no existe inversión por parte de la convocada para el desarrollo de la expansión de la convocante. Por el contrario, esta última entrega en arriendo o en comodato los elementos propios de la estación de servicio para su operación, así como el propio establecimiento de comercio. Pero, independiente de la naturaleza del contrato aquí analizado, las pretensiones de la demanda se refieren a la existencia de negocios jurídicos entre la convocante y los convocados: Marina Fandiño de Rubio y Carlos Guillermo Rubio Fandiño, negocios que no son desconocidos por la parte convocada; por el contrario, reconoce su existencia (aunque alega su invalidez por carencia de facultades para comprometer a la convocante, lo cual ya se respondió anteriormente). Siendo ello así, la presente excepción tampoco está llamada a prosperar". Centro de Arbitramento de la Cámara de Comercio de Bogotá, Chevron Petroleum Company vs. Mariana Fandiño de Rubio y Carlos Guillermo Rubio-Fandiño, laudo arbitral de 16 de septiembre de 2008.

31 Centro de Arbitramento de la Cámara de Comercio de Bogotá, División Mayor del Fútbol Colombiano, Dimayor vs. Radio Cadena Nacional S. A., RCN y Caracol Televisión S. A., laudo arbitral de 6 de junio de 2001.

32 La diferencia fue establecida en el siguiente sentido: "El convenio celebrado se acerca, más bien, a aquellas especies contractuales cuyo objeto consiste en poner en cabeza de otro un derecho que se tiene, para que quien lo recibe pueda ejercerlo, o aprovecharse o beneficiarse de él, como serían, entre otras, el suministro, la agencia comercial, la franquicia, la concesión o el arrendamiento. Sin embargo, con las tres primeras - suministro, agencia y franquiciaofrece diferencias importantes: con el suministro porque el derecho que se otorgó a cambio de la remuneración no constituye, propiamente hablando, una 'prestación periódica o continuada de cosas o servicios', como lo exige el artículo 968 del Código de Comercio, en cuanto la Dimayor, desprendida temporalmente de su derecho, no realiza ni tiene a su cargo prestación alguna, amén de que el suministro se resuelve en ventas continuas o periódicas, es decir, en 
Por tanto, para la jurisdicción arbitral dos elementos contractuales hacen parte de la esencia del contrato de franquicia, y por consiguiente lo diferencian del contrato de agencia, suministro y arrendamiento: (i) la autonomía que posee el franquiciante; y (ii) la transferencia de la marca y el know-how, a cualquier título.

Por su parte, la Superintendencia de Industria y Comercio, SIC, en uso de sus facultades consultivas, también se ha pronunciado respecto el contrato de franquicia. En el concepto 133956 de 2011, la SIC resolvió la siguiente inquietud, presentada a esta autoridad: ¿La Superintendencia de Industria y Comercio (SIC) puede registrar los contratos de franquicia debidamente celebrados en Colombia?".

Teniendo en cuenta la anterior pregunta, la Superintendencia procedió a señalar las atribuciones conferidas en virtud del "Decreto 3523 de 2009, modificado por el Decreto 1687 de 2010, mediante el cual se consagra que no tiene facultad para inscribir contratos de franquicia celebrados en Colombia. En tal sentido, podría inscribir en el registro de la propiedad industrial como licencia de uso". De la misma manera, procede a definir el contrato de franquicia y concluye afirmando que "el contrato puede incluir la licencia de uso de un bien protegido por la propiedad industrial que bien podría ser sobre su marca".

De igual forma, en el concepto 1212079400000000 del 18 de julio de 2012, la Superintendencia con base en la doctrina resolvió los interrogantes relacionados con la responsabilidad ${ }^{33}$ del franquiciante frente a los consumidores del franquiciado y frente a terceros; sobre el registro del contrato de licencia ubicados en Colombia y

\footnotetext{
transferencias de propiedad. Con la agencia comercial tiene diferencias porque ninguna de las partes actúa como 'representante o agente de un empresario nacional o extranjero o como fabricante o distribuidor de uno o varios productos del mismo', que son las notas tipificantes de la agencia entre nosotros conforme al artículo 1317 del Código de Comercio. Y se separa de la franquicia porque no habría distribución de un producto o un servicio bajo la marca o el nombre de quien la otorga, ni la utilización o aprovechamiento por el 'franquiciado' del know-how del 'franquiciante', marca y saber-hacer que son los elementos fundamentales de la moderna figura (ANTONIO VANEGAS-SANTORO, El contrato de franquicia, 61 ss. (Ediciones Librería del Profesional, Bogotá, 1999))". Centro de Arbitramento de la Cámara de Comercio de Bogotá, División Mayor del Fútbol Colombiano, Dimayor vs. Radio Cadena Nacional S. A., RCN y Caracol Televisión S. A., laudo arbitral de 6 de junio de 2001.

33 Frente a la vigilancia de los contratos de franquicia, la Superintendencia de Industria y Comercio, mediante concepto 13-095570, del 28 de mayo de 2013, señaló: "No existe una entidad encargada de vigilar en sí a las franquicias en Colombia. Sin embargo, si estas realizan actuaciones de competencia desleal, o incurren en alguna otra conducta violatoria de los Estatutos, y de la cual es encargada de vigilar una Superintendencia del Estado colombiano, eventualmente la misma vigilará la franquicia en Colombia”.
} 
en el extranjero. Frente a lo cual respondió en el primer caso que: "En los contratos de franquicia se aplica el Régimen de Protección al Consumidor de la Ley 1480 de 2011, donde el productor y/o proveedor responden solidariamente ante los consumidores, lo cual en principio no sugiere que el franquiciante responda ante los consumidores del franquiciador, pues debe entrarse a estudiar frente a qué tipo de franquicia nos encontramos. Así pues, si el franquiciador desarrolla una franquicia del tipo en la cual es productor, responde solidariamente ante los consumidores, junto con el franquiciante, que funge como proveedor".

Por otra parte, en cuanto al registro debe tenerse en cuenta que "para el registro de licencias de patentes, según dispone la Decisión 486 de la CAN (artículo 57), no debe tenerse en cuenta el domicilio del licenciado ni del licenciatario, sino la oficina del país que concedió la patente. Este es un trámite opcional. Según el trámite del Capítulo Uno del Título Décimo de la Circular Única de la Superintendencia de Industria y Comercio".

En adición a lo antes expuesto, también es importante resaltar que en Colombia, la falta de regulación expresa de esta figura ha llevado a los gremios interesados en esta temática a la creación de un Código de Ética para las Franquicias, auspiciado por la Cámara Colombiana de Franquicias ${ }^{34}$, y la expedición por parte del Instituto Colombiano de Normas Técnicas y Certificación, ICONTEC, de la norma técnica colombiana NTC 5813, la cual trata los requisitos generales para la etapa precontractual, contractual y poscontractual de una franquicia. Estos instrumentos pertenecen al denominado soft law y desde ese punto de vista, no son vinculantes, aunque sirven de guía para quienes interactúan en el mercado de las franquicias.

Así las cosas, la franquicia como método de negocios está en construcción y crecimiento. Marcela Castro-Ruiz, Carlos Julio Giraldo-Bustamante, Nelson Remolina-Angarita y Juan Carlos

34 Este código, que entró en vigencia el 4 de diciembre de 2012, se fundamenta en el Código Deontológico, de la Asociación Europea de Franquicias. En esencia, este código define tanto franquicia como contrato de franquicia, establece las obligaciones de las partes, determina los lineamientos frente a la captación de franquiciados, publicidad, información, la selección de franquiciados, y el sistema de franquicia maestra. Cámara Colombiana de Franquicias, Código de Ética para las Franquicias, 4 de diciembre de 2012. Disponible en: http://www. colfranquicias.com/la-asociacion/codigo-de-etica.html. Asociación Europea de Franquicias, Código Deontológico, 1 de enero de 1991. Disponible en: http://www.guia.ceei.es/archivos/ Documento/Codigo_Deontologico_Europeo_franquicia.pdf 
VARÓN-PALOMino consideran que este esquema de negocio seguirá progresando en el país en la medida en que Colombia no solo es atractivo como país receptor de franquicias, sino también como país exportador de las mismas. Este fenómeno se muestra como consecuencia de la política de liberalización comercial que ha tenido Colombia con la Comunidad Andina, la Unión Europea y el Tratado de Libre Comercio con Estados Unidos ${ }^{35}$.

Las cifras también respaldan estas afirmaciones. En Colombia, para 2005, este tipo de negocio jurídico generaba 34.000 empleos directos y 13.684 empleos indirectos. Estas cifras, comparadas con las de 2004, representaron un crecimiento en materia de empleos directos del 26,0\% y de empleos indirectos del 15,8\% $\%^{36}$.

De igual forma, ha habido un aumento de los negocios de franquicia en Colombia. Hasta 2008, el sector experimentó un crecimiento del 18\%. En 2009, tuvo una disminución de 1,6\% producto de la crisis económica mundial de ese año, pero para 2010 el crecimiento fue de $10,33 \%{ }^{37}$. Durante 2011, el sector creció un 4,0\%. Para el final de 2011, Colombia tenía 427 franquicias, de las cuales un $48,7 \%$ son marcas extranjeras. De ese porcentaje, el 20,4\% pertenece a compañías estadounidenses. Los sectores que más se han beneficiado de este sistema de negocios son los restaurantes de comida rápida, los almacenes de ropa y los productos para el hogar. Se espera la expansión de este modelo de negocios al sector servicios en actividades como educación, consultoría, turismo, transporte, entre otros ${ }^{38}$. A junio de 2014, en Colombia había 532 franquicias, de las cuales $41 \%$ pertenecía al mercado doméstico frente a $59 \%$ de franquicias internacionales; sobresalían las confecciones y entre estas, las estadounidenses son las más comunes ${ }^{39}$.

35 Marcela Castro-Ruiz, Carlos Julio Giraldo-Bustamante, Nelson Remolina-Angarita \& Juan Carlos Varón-Palomino, Contratos atípicos en el derecho contemporáneo colombiano, 18 (Universidad de Los Andes, Facultad de Derecho, Cámara de Comercio de Bogotá, CCB, Fundación Universitaria Empresarial de la Cámara de Comercio de Bogotá, Uniempresarial, Bogotá, 2006).

36 Felipe Mosquera-Muñoz, La franquicia, una estrategia de crecimiento empresarial, 1 Revista MBA EAFIT, 70-85, 76 (2010). Disponible en: http://www.eafit.edu.co/revistas/revistamba/ Documents/franquicia-estrategia-crecimiento-empresarial.pdf

37 Cifras de la International Franchise Association: http://www.franchise.org/Franchise-NewsDetail.aspx?id=55937

38 Cifras de Export.gov: http://export.gov/colombia/doingbusinessincolombia/sellingusproducts andservices/index.asp

39 Cifras del portal Mas Franquicias: http://www.masfranquicias.com/cifras-de-la-franquiciaen-colombia/ 
Al respecto, JAVIER OrLANDo Gordillo, gerente de Desarrollo Empresarial Colombiano, Desacol Franquicias, ha apuntado que la apertura económica ha obligado a los empresarios colombianos a mirar nuevos mercados, en especial los internacionales, a modernizar su comercio, a mejorar cada día su control de calidad, a una mayor competitividad y a aplicar la franquicia como una forma de expansión empresarial ${ }^{40}$.

\section{B. El contrato de franquicia en Estados Unidos}

Por otro lado, el contrato de franquicia en Estados Unidos no es un contrato atípico, aunque está regulado en forma dispersa en normas federales y estatales ${ }^{41}$. La Federal Trade Commission (en adelante, FTC) hace la regulación federal, por medio de la Franchise Rule, y la Sección 5 de la Federal Trade Commission Act. En cuanto a la regulación estatal, cada estado adopta su propia legislación; sin embargo, la normatividad se centra en los deberes precontractuales de información (Franchise Disclosure Duties) ${ }^{42}$. De igual forma, otros tipos de leyes como las leyes antitrust federales y estatales, como la Sherman Antitrust Act, también regulan este contrato ${ }^{43}$.

De acuerdo con William A. Gregory y Thomas R. Hurst, la normatividad — estatal y federal — regula específicamente la relación franquiciante-franquiciado, al establecer parámetros para la revelación de información por parte del franquiciante a los poten-

40 FABIÁn López-GuZmán, El contrato de franquicia internacional. Un modelo estratégico empresarial, 30 (Ediciones Jurídicas Gustavo Ibáñez, Bogotá, 2005).

41 Karsten MetzlafF, Norman Issley y Gaylen KNACK señalan que la legislación estadounidense en materia de franquicia parece una colcha de retazos por la multiplicidad de regulaciones federales y estatales. Karsten Metzlaff, Norman Issley \& Gaylen Knack, Adapting Civil and Common Law Contracts to the U.S. Market, 10 International Journal of Franchising Law, 5, 3-29 (2012).

42 La principal regulación del contrato de franquicia en Estados Unidos se realiza desde el punto de vista de la responsabilidad precontractual del franquiciante frente al franquiciado por la no divulgación de información vital para que este tome la decisión de comprar o no la franquicia. Esta normatividad relativa a la franquicia y los deberes precontractuales de revelación, tanto estatales como federales, tiene su motivación en la protección del franquiciado como consumidor. Por ejemplo, la Ley de Franquicia del Estado de Nueva York declara al respecto, en la sección 680, que la oferta y venta de franquicias es un asunto de interés público, pues se busca fundamentalmente proteger a aquellos franquiciados que han sido víctimas de ventas fraudulentas, cuando el franquiciante no provee toda la información completa relativa a la relación franquiciante-franquiciado, los detalles del contrato, su experiencia previa, etc.

43 Ralph Folsom, Michael Wallace-Gordon \& John A. Spanogle, International Business Transactions in a Nutshell, 192 (8 ed., West Academic Publishing, Saint Paul, Minnesota, 2009). 
ciales franquiciados ${ }^{44}$. De igual forma, regula en forma extensiva la terminación y renovación de franquicias. En el ámbito estatal, se regula la terminación de franquicias por franquiciantes en general y, en la mayoría de los casos, se exige que el franquiciante alegue una justa causa para tal acción. Adicionalmente, el contrato de franquicia también es regulado por leyes federales y estatales de derecho de la competencia, derecho marcario, contratos y responsabilidad civil extracontractual, e incluso existe la posibilidad de regulación por medio de los principios de la agencia, por la posible responsabilidad subsidiaria atribuible al franquiciante por actos del franquiciado que causen daños a terceros.

En este contexto, en la legislación estadounidense se entiende por contrato de franquicia:

cualquier relación comercial continua o acuerdo, sin importar su denominación, en la cual los términos de la oferta o contrato especificado, o en el cual el vendedor de la franquicia prometa o represente, oralmente o por escrito que: (1) el franquiciado obtendrá el derecho de operar un negocio identificado o asociado con la marca del franquiciante, o para ofrecer, vender o distribuir bienes, servicios, o materias primas, que se identifican o asocian con la marca del franquiciante; (2) el franquiciante ejercerá o tendrá la potestad de ejercer un grado de control significativo sobre el método de operación del franquiciado, o proveerá significante asistencia en el método de operación de la franquicia; y (3) como condición para obtener o comenzar la operación de la franquicia, el franquiciado realiza un pago o se compromete a realizar un pago requerido por el franquiciante o su afiliado ${ }^{45}$.

Este concepto considera como elementos esenciales del contrato de franquicia en Estados Unidos el licenciamiento de la venta o distribución de bienes y/o servicios por medio de un sistema, el licenciamiento de marcas y la transferencia de know-how, el pago de una regalía a cambio de ese licenciamiento, y la supervisión operativa por parte del franquiciante ${ }^{46}$. Ahora bien, el negocio de

44 Cifras de la International Franchise Association: http://www.franchise.org/Franchise-NewsDetail.aspx?id=58916\#

45 Estados Unidos, Code of Federal Regulations, CFR, 16 CFR part. 436, 72 FR 15544, Mar. 30, 2007 (traducción libre). Disponible en: https://www.gpo.gov/fdsys/browse/collectionCfr. action? collectionCode $=$ CFR

46 En el ámbito estatal, por ejemplo, en California, la Franchise Investment Law dispone como elementos "esenciales" del contrato de franquicia la concesión al franquiciado el derecho de ofrecer, vender o distribuir bienes o servicios dentro de un plan de mercadeo determinado en gran parte por el franquiciador; la asociación de la operación comercial del franquiciado 
franquicia en Estados Unidos ha tenido un gran auge en las últimas décadas, y se ha convertido en un sector importante en la economía de ese país ${ }^{47}$. Al respecto, Osvaldo J. Marzorati ha señalado que "actualmente la franquicia es el método más utilizado en los Estados Unidos de América por el mercado minorista, respondiendo a cerca del 65\% de la distribución en el sector de bienes de consumo"48. De acuerdo con MATTHEw SHAY, presidente y CEO de la International Franchise Association (IFA), entre 2001 y 2005, el sector de franquicias creció $18 \%$ y se generaron 140.000 nuevos negocios y 1,2 millones de nuevos trabajos a la economía de Estados Unidos, incluyendo el sector financiero y manufacturero ${ }^{49}$.

En relación con este tema, Jill SCHACHNER-CHANEN ${ }^{50}$ presenta un análisis de cifras que revelan la importancia que ha ido adquiriendo el negocio de franquicias en Estados Unidos. Así, para 1960, la franquicia representaba US\$60.000 millones de dólares de facturación anual, aproximadamente y para 1975, la cifra aumentó a US\$240.000 millones de dólares, lo que representaba el $20 \%$ del producto bruto nacional y $31 \%$ de todas las ventas minoristas. Para 2000, de acuerdo con estimaciones de la IFA, el 50\% de las ventas minoristas se hizo utilizando este sistema de negocios. Para 2005, los negocios franquiciados sumaban 750.000 en 75 tipos de actividades diferentes y generaban casi 10.000 .000 de empleos directos y 18.000.000 de empleos indirectos, según PriceWATER houseCoOPERS.

a la marca, nombre, logotipo, publicidad o cualquier otro símbolo comercial distintivo del franquiciador o sus afiliados; y el pago, de manera directa o indirecta, de un canon o regalía, por parte del franquiciado (Sección 31005). WARREN PENGILLEY ha señalado que el concepto de franquicia envuelve el uso por el franquiciado de una marca o logo perteneciente al franquiciante, la concesión, por parte del franquiciante al franquiciado, del derecho a vender o usar o sistema desarrollado, producto o servicio, y el pago de regalías. WARRen PengiLley, International Franchising Arrangements and Problems in their Negotiation, 7 Northwestern Journal International Law \& Business, 2, 185-207, 187 (1985). Disponible en: http://scholarlycommons. law.northwestern.edu/cgi/viewcontent.cgi?article $=1196 \&$ context $=$ njilb

47 Ralph Folsom, Michael Wallace-Gordon \& John A. Spanogle, International Business Transactions in a Nutshell, 191-192 (8 ed., West Academic Publishing, Saint Paul, Minnesota, 2009). Estos autores estiman que la tercera parte de las ventas minoristas en Estados Unidos se hace por medio de franquicias. Los franquiciantes estadounidenses han encontrado que la franquicia es una forma de penetración de mercado en el exterior (traducción libre).

48 Osvaldo J. Marzorati, Sistemas de distribución comercial, 236 ( $3^{\mathrm{a}}$ ed., Astrea, Buenos Aires, 2011).

49 Tomado de la International Franchise Association: http://www.franchise.org/Franchise-NewsDetail.aspx?id $=39252$

50 Osvaldo J. Marzorati, Sistemas de distribución comercial, 236 ( $3^{\mathrm{a}}$ ed., Astrea, Buenos Aires, 2011). Jill Schachner-Chanen, Growing Pains for Franchise Law, American Bar Association Journal (April 2006). 
Para 2013, las proyecciones no fueron tan halagadoras como en años previos. Sin embargo, de acuerdo con la IFA, en su proyección para 2012, el crecimiento de establecimientos de franquicia será de 1,4\% con respecto al 1,5\% de $2012^{51}$. Entre otras, se le atribuye el lento crecimiento en ese año a la recesión económica que había venido experimentando la economía estadounidense.

\section{Incidencias del TLC en el contrato de franquicia internacional}

Tomando en cuenta este contexto, la entrada en vigor del TLC entre Colombia y Estados Unidos ha generado una gran expectativa de aumento de oportunidades de negocios para quienes trabajan en el sector de las franquicias en ambos países ${ }^{52}$. Al respecto, con la firma del TLC, la embajada de Estados Unidos en Bogotá ha venido promocionando la visita de misiones de empresas estadounidenses a Colombia con el ánimo de que establezcan franquicias en el país; por tanto, es de esperarse que empresas de renombre internacional establezcan nuevos negocios en Colombia utilizando este medio ${ }^{53}$.

Sin embargo, también debe esperarse que surjan conflictos jurídicos derivados de la controversia que hay en ambos países en cuanto al modelo regulatorio del contrato de franquicia, en la medida en que en Estados Unidos tiene un modelo multirregulatorio, pues hay regulación tanto federal como estatal, mientras que en Colombia la franquicia pertenece a un modelo autorregulatorio, en donde las partes bajo el principio de autonomía de la voluntad establecen sus propias normas y obligaciones. Así las cosas, este TLC ha creado una expectativa de problemas jurídicos en cuanto

51 Cifras de la International Franchise Association: http://www.franchise.org/Franchise-NewsDetail.aspx?id=58916\#

52 En 2013, Nicole DeSilvis, agregada comercial de la embajada de Estados Unidos, señaló: "los empresarios de Estados Unidos están interesados en desarrollar franquicias en Colombia" y "en los últimos dos años se ha reforzado el trabajo orientado a promover esta figura comercial". El Heraldo, Avanza TLC: empresarios de EU ofrecen franquicias en Colombia, El Heraldo, Economía, Barranquilla, 14 de febrero de 2013. Disponible en: http://www.elheraldo. co/noticias/economia/avanza-tlc-empresarios-de-eu-ofrecen-franquicias-en-colombia-100109

53 Empresas como Fuddruckers, Popeyes LouisianaKitcken, McAlister's Deli, TheMeltingPot, Jani-King International y Hertz Equipment Rental Corp. han mostrado interés en ello. US Embassy Bogotá (19 de julio de 2012). FTA also Opens Up Opportunities in Franchising. Disponible en: http://usbusiness-opportunities-embassybogota.com/2012/07/19/fta-also-opensup-opportunities-in-franchising/ 
a la interpretación y aplicación no solo de las normas de propiedad intelectual relativas a marcas, patentes, transferencia de know-how, terminación del contrato, solución de controversias, entre otras, sino también con respecto a los conflictos de leyes que puedan surgir de estos contratos y a la interpretación que jueces y Cortes les den a los problemas jurídicos resueltos por ambas legislaciones en forma distinta.

En este sentido, en su anexo 11-E Agencia Comercial, el TLC explora un primer problema jurídico consistente en la determinación de la indemnización a la terminación sin justa causa del contrato de agencia mercantil. No obstante, dada la similitud de este contrato con el contrato de franquicia, las provisiones allí descritas podrían afectarlo, sobre todo si se tiene en cuenta que de acuerdo con el numeral 5 literal $\mathrm{b}$ del anexo 11-E, contrato de agencia comercial significa "para los Estados Unidos, cualquier contrato en que una parte acuerde distribuir bienes comerciales para otra parte". En ese orden de ideas, si se tratase de una franquicia de distribución, por ejemplo, una franquicia de textiles, para efectos de este tratado se asimilaría a un contrato de agencia mercantil, trayendo como consecuencia que las reglas previstas para el contrato de agencia mercantil como se entiende en Colombia, también se le aplicarían a este.

Así las cosas, el TLC impone a los Estados parte la obligación de modificar o derogar normas que prevean pagos al agente una vez terminada la relación contractual, indemnizaciones equitativas a favor del agente por terminación del contrato sin justa causa por parte del principal, o con justa causa por parte del agente, y la creación de una agencia exclusiva en virtud del contrato de agencia, salvo pacto en contrario.

En cuanto al pago de las indemnizaciones por terminación del contrato, el TLC establece que estas deben determinarse de conformidad con "(i) los principios generales del derecho contractual (por ejemplo, costos no recuperados, lucro cesante y detrimental reliance)" y de acuerdo a lo que las partes pacten en el contrato, "en la medida en que sean compatibles con las leyes aplicables".

Como resultado, la terminación unilateral de un contrato de franquicia, bajo los términos del tratado, debería regirse por los 
principios generales del derecho contractual y lo pactado por las partes en el mismo.

En esta misma línea, el TLC entre Colombia y Estados Unidos prevé la posibilidad de controversias comerciales entre particulares, y para estos efectos consagra en el artículo 21.22 del capítulo 2 que para controversias entre particulares los Estados partes se comprometen a promover y facilitar el arbitraje y otros medios alternos de solución de diferencias, así como a disponer de procedimientos adecuados que aseguren la observancia de convenios de arbitraje y el reconocimiento y ejecución de laudos arbitrales.

Esta norma, claro está, no es de exclusiva aplicación para los contratos de franquicia internacional, pero denota que en este tipo de contratos la promoción de acuerdos de arbitraje internacional será (o al menos, debe ser) una prioridad en esta materia de los gobiernos involucrados.

Por otro lado, otro problema jurídico que podría surgir del aumento de relaciones de franquicia, producto de la firma del TLC, se relaciona con el deber precontractual de información. Así, a diferencia de lo que ocurre en el régimen legal colombiano, en el régimen legal de Estados Unidos, la ley de manera expresa dispone el deber precontractual de información por parte del franquiciador ${ }^{54}$. Entonces, mientras en Colombia un problema jurídico relativo a declaraciones engañosas por parte del franquiciante hacia el franquiciado sobre aspectos como la real rentabilidad de una franquicia, tendría que resolverse mediante las normas generales de las obligaciones, en Estados Unidos esa problemática tiene su propia regulación.

A este respecto, la FTC tiene entre sus mandatos, prevenir prácticas injustas y engañosas que afecten el comercio ${ }^{55}$. Para ello, ha dispuesto que el franquiciante debe entregar al franquiciado el franchise disclosure document, que debe consignar la información requerida de manera exacta, completa, accesible y a tiempo. En este sentido, el incumplimiento del deber de información en Estados

54 María Fernanda Navas-Herrera \& Andrés Mauricio Mosquera-Moreno, El contrato de franquicia: aportes y tendencias en el derecho comprado sobre la responsabilidad el franquiciador, 119 Revista Vniversitas, 279-304, 283 (2009). Disponible en: http://www.scielo.org.co/pdf/vniv/ n119/n119a17.pdf

55 Estados Unidos, Federal Trade Commission Act, 15 U.S.C. $\S \S 41-58$, as amended, § 5. Disponible en: https://www.ftc.gov/es/enforcement/statutes/federal-trade-commission-act 
Unidos genera sanciones fuertes en los ámbitos federal y estatal, que van desde sanciones administrativas hasta sanciones civiles y penales $^{56}$.

Ahora bien, autores como Ralph Folsom, Michael WallaceGordon y John A. Spanogle han advertido que cuando se trata de un contrato de franquicia internacional, se presenta una gran variedad de problemas jurídicos que van desde asuntos de propiedad intelectual, derecho de la competencia, impuestos y licencias hasta la revisión de los contratos estándar de franquicias sin alterar significativamente la fórmula del éxito del negocio del franquiciante y en la cual se deben especificar asuntos como las regalías, el entrenamiento, el control del franquiciante, el territorio y la solución de controversias, entre otros ${ }^{57}$.

Al respecto, FABIÁN LóPEZ-GUZMÁN ${ }^{58}$ vaticinó antes de la entrada en vigencia del TLC con Estados que su proximidad debía "significar un llamado de alerta al Estado, a los empresarios titulares de franquicias locales y a los empresarios nacionales que explotan franquicias internacionales, para ponerse a la altura de los tiempos. Advirtiendo que debía tenerse un conocimiento amplio en materias como derecho de la competencia, y estar preparados so pena

56 Joel R. Buckberg \& Jillian M. Suwanski, Disclosure Law Violations: Understanding the Penalties, 40 Franchising World, 8 (2008). Disponible en: http://www.franchise.org/FranchiseNews-Detail.aspx?id=41926

57 Ralph Folsom, Michael Wallace-Gordon \& John A. Spanogle, International Business Transactions in a Nutshell, 193 (8 ed., West Academic Publishing, Saint Paul, Minnesota, 2009). SILVANA InSIgNARES-CERA explica que los principales conflictos que pueden extraerse de un contrato de franquicia internacional (en el marco de un TLC como el suscrito entre Colombia y Estados Unidos) se relacionan con responsabilidad civil, propiedad intelectual, tributación y libre competencia. Silvana Insignares-Cera, Principales conflictos contractuales derivados de la ejecución del contrato de franquicia internacional en el marco del TLC Colombia-USA, en Contrato de franquicia internacional en el marco del TLC Colombia-USA, perspectivas jurídicas y económicas, 27-59, 42 (SilvanA InSIGNARES-CERA, ed., Universidad del Norte, ECOE Ediciones, Bogotá, 2015). Otros autores también exponen problemas jurídicos alrededor del contrato de franquicia internacional: FABIÁN LÓPEZ-GUZMÁN apunta como los inconvenientes más frecuentes derivados del contrato de franquicia internacional el número elevado de rescisiones contractuales por incumplimiento del franquiciado, la facilidad de incurrir en publicidad engañosa y la ausencia de norma uniforme para proteger al franquiciado en esa materia. FABIÁN LóPEZ-GUZMÁN, El contrato de franquicia internacional. Un modelo estratégico empresarial, 151 (Ediciones Jurídicas Gustavo Ibáñez, Bogotá, 2005). Osvaldo J. Marzorati, Sistemas de distribución comercial, 278 ( $3^{\mathrm{a}}$ ed., Astrea, Buenos Aires, 2011). Este autor señala que "las leyes que regulan la responsabilidad por el producto, los seguros, garantías y otros aspectos similares pueden ser los aspectos legales más importantes de una operación de franquicia. Un conocimiento de tales leyes en el país donde se establecerá la franquicia es de suma importancia para un franquiciante extranjero".

58 FABí́n López-GuzMÁn, El contrato de franquicia internacional. Un modelo estratégico empresarial, 30 (Ediciones Jurídicas Gustavo Ibáñez, Bogotá, 2005). 
de fracasar estrepitosamente, teniendo en cuenta que con el TLC con Estados Unidos se insertarían al mercado nacional una gran variedad de franquicias. De igual forma, señaló que la legislación colombiana debía armonizarse con la realidad de la economía global y realizar un análisis de los mecanismos procesales y los controles a fenómenos nocivos a la importación, la explotación de una situación de dependencia económica, los boicots, etc.”.

Finalmente, en materia de propiedad intelectual, el TLC entre Colombia y Estados Unidos incide en al menos dos aspectos en la regulación del contrato de franquicia internacional. El primero de ellos tiene qué ver con el registro de la licencia de una marca, la cual puede obedecer a un contrato autónomo o generarse como consecuencia de un contrato de franquicia. Como lo hemos mencionado, en Estados Unidos hay unas obligaciones específicas relacionadas con la obligatoriedad del registro por parte de los franquiciadores, y la obligación de suministrar la información relativa al contenido del contrato ${ }^{59}$, mientras que en el derecho colombiano — según la Superintendencia de Industria y Comercio ha manifestado- no hay requerimiento alguno que indique que el contrato de franquicia deba ser inscrito ante una autoridad nacional, tan solo se requiere la inscripción de las licencias para el uso de los nombres, marcas, patentes, know how y, en general, las licencias para el uso de cualquier elemento del contrato que implique propiedad intelectual ${ }^{60}$.

59 Marco Peres-Useche, Franquicias: derecho uniforme y tecnologías de información, en Derecho internacional de los negocios: alcances. Homenaje a Fernando Hinestrosa, 40 años de rectoría 1963-2003, Tomo I, 209-228 (Adriana Zapata de Arbeláez, comp., Universidad Externado de Colombia, Bogotá, 2010). Disponible en: http://www.youblisher.com/p/597216-DerechoInternacional-de-los-Negocios-alcances-Tomo-I/

60 Así lo expresó la Superintendencia de Industria y Comercio en el concepto 133956 de 2011, al resolver la inquietud: "¿La Superintendencia de Industria y Comercio (SIC) puede registrar los contratos de franquicia debidamente celebrados en Colombia?". La entidad señaló las atribuciones conferidas en virtud del Decreto 3523 de 2009, modificado por el Decreto 1687 de 2010, mediante el cual se consagran las funciones de la Superintendencia de Industria y Comercio, no contempla la facultad de esta para inscribir contratos de franquicia celebrados en Colombia. En tal sentido, podrían inscribirse en el registro de la propiedad industrial como licencia de uso. De la misma manera, la Superintendencia se propuso definir el contrato de franquicia, concluyendo que "el contrato puede incluir la licencia de uso de un bien protegido por la propiedad industrial que bien podría ser sobre su marca". En cuanto a la vigilancia de la ejecución del contrato de franquicia, la Superintendencia de Industria y Comercio dispuso: "No existe una entidad encargada de vigilar en sí a las franquicias en Colombia. Sin embargo, si estas realizan actuaciones de competencia desleal, o incurren en alguna otra conducta violatoria de los Estatutos, y de la cual es encargada de vigilar una Superintendencia del Estado colombiano, eventualmente la misma vigilará la franquicia en Colombia”, así lo expuso mediante concepto 13-095570 del 28 de mayo de 2013. 
A este respecto, el TLC entre Colombia y Estados Unidos ha eliminado la obligación del registro al consagrar en su artículo 16:2, numeral 12 que: "Ninguna de las partes requerirá el registro de las licencias de marca para establecer la validez de las licencias, para afirmar cualquier derecho de la marca, o para otros propósitos". Así las cosas, cuando se trate de un contrato de franquicia internacional entre partes con domicilio en Estados Unidos y Colombia, el contrato de franquicia, como tal, deberá ser objeto o no de registro dependiendo de la legislación aplicable, pero las autoridades no podrán exigir el registro de la licencia de marca que este contrato envuelve.

El segundo aspecto gira en torno a la obligación que Colombia adquirió en virtud del TLC con Estados Unidos, de adherirse al Protocolo concerniente al Arreglo de Madrid relativo al Registro Internacional de Marcas ${ }^{61}$, que establece la solución centralizada para el registro y la gestión de las marcas en todo el mundo ${ }^{62}$. Este tema merece una mayor atención por parte de autoridades gubernamentales, comerciantes y la academia porque la adhesión a ese tratado además de ofrecer la oportunidad de registrar tanto marcas internacionales en el país como marcas colombianas en los países miembros del Protocolo de Madrid, tendrá como efecto el aumento de compras o licenciamientos de marcas extranjeras en Colombia, lo cual producirá el incremento de contratos de franquicia internacional en el país, aunque además podrá traer consecuencias no previstas para la industria nacional en la medida en que las marcas colombianas podrían no estar preparadas para esta situación ${ }^{63}$.

61 Organización Internacional de Propiedad Intelectual, OMPI, Protocolo concerniente al Arreglo de Madrid relativo al Registro Internacional de Marcas, adoptado en 1891, revisado en Bruselas (1900), en Washington (1911), en La Haya (1925), en Londres (1934), en Niza (1957) y en Estocolmo (1967), y enmendado en 1979; y el Protocolo concerniente a ese Arreglo, adoptado en 1989. Disponible en: http://www.wipo.int/export/sites/www/madrid/es/legal_texts/ pdf/madrid_protocol.pdf, http://www.wipo.int/treaties/es/registration/madrid_protocol/. En Colombia, la ley aprobatoria del tratado es la Ley 1455 de 2011. Colombia, Ley 1455 de 2011, por medio de la cual se aprueba el Protocolo concerniente al arreglo de Madrid relativo al Registro Internacional de Marcas, adoptado en Madrid el 27 de junio de 1989, modificado el 3 de octubre de 2006 y el 12 de noviembre de 2007, 48.116 Diario Oficial, 30 de junio de 2011. Disponible en: http://www.secretariasenado.gov.co/senado/basedoc/ley_1455_2011.html

62 Superintendencia de Industria y Comercio, Propiedad industrial 2020, 65-67 (Superintendencia de Industria y Comercio, Bogotá, 2012). Disponible en: http://www.sic.gov.co/recursos_user/ documentos/publicaciones/Libro_PI_2020/files/libro\%20propiedad\%20industrial\%202020. $\mathrm{pdf}, \mathrm{http} / / /$ issuu.com/quioscosic/docs/propiedad_industrial_2020

$63 \mathrm{Al}$ respecto, el analista CAmilo Herrera-Mora ha señalado que las marcas colombianas no están listas para el TLC con Estados Unidos y que con la entrada de Colombia al Acuerdo 


\section{PROPUESTA PARA LOGRAR LA CONVERGENCIA DE REGULACIONES DEL CONTRATO DE FRANGUICIA ENTRE COLOMBIA Y ESTADOS UNIDOS}

Conforme a lo expuesto, debido a la divergencia en cuanto a la regulación del contrato de franquicia en Colombia y Estados Unidos, como resultado de la ejecución y/o implementación del mismo, en el marco del desarrollo del TLC COL-USA, pueden generarse controversias derivadas principalmente de: (i) vacíos normativos para la regulación de ciertos aspectos puntuales al contrato; (ii) riesgos que surgen del contrato, y la asunción de los mismos; y (iii) la jurisdicción y legislación aplicable al contrato por contener elementos extranjeros o internacionales.

Además de ello, si se analiza el contexto del derecho del comercio internacional, el contrato de compraventa internacional de mercaderías es el único acto jurídico que posee un cuerpo normativo autónomo para regular las obligaciones y derechos surgidos del mismo, la Convención de las Naciones Unidas sobre los Contratos de Compraventa Internacional de Mercaderías de $1980^{64}$. No obstante, en cuanto a los contratos de colaboración empresarial ${ }^{65}$, entre los cuales está el contrato de franquicia internacional, estos no poseen una normativa internacional de carácter vinculante que regule las relaciones mercantiles derivadas de él, quedando solo las guías y usos uniformes y, por supuesto, las normas generales

de Madrid, marcas internacionales harán su aparición en el país, lo que generará el aumento de compra de marcas extranjeras. Así, sugiere el analista como punto fundamental revisar el tema de las franquicias. CAmilo Herrera-Mora, ¿ Nuestras marcas están listas para el TLC con Estados Unidos?, Diario La República (13 de marzo de 2013). Disponible en: http://www.larepublica.co/ $\% \mathrm{C} 2 \%$ BFnuestras-marcas-est $\% \mathrm{C} 3 \% \mathrm{~A} 1 \mathrm{n}$-listas-para-el-tlc-con-estados-unidos_4145

64 ENRIQUE GUARDIOLA-SACARRERA, La compraventa internacional: importaciones y exportaciones, 40 (Bosch, Barcelona, 2001). Organización de las Naciones Unidas, ONU, Convención de las Naciones Unidas sobre los Contratos de Compraventa Internacional de Mercaderías de 1980 (Organización de las Naciones Unidas, Nueva York, 2011). Disponible en: https://www. uncitral.org/pdf/spanish/texts/sales/cisg/V1057000-CISG-s.pdf

65 Los contratos de colaboración empresarial son instrumentos jurídicos en los cuales se materializa una integración parcial o cooperación entre empresas independientes. Así, no hay en el derecho comercial positivo colombiano una categoría normativa precisa para este tipo de relaciones jurídicas. Se trata más bien de un fenómeno económico y administrativo, que se observa en la vida diaria de las empresas, al que se aplican diferentes reglas jurídicas, según sean los instrumentos legales que las partes hayan decidido adoptar en un momento determinado. Jaime Alberto Arrubla-Paucar, Contratos mercantiles III, Tomo I, 58 (Diké, Medellín, 2006). 
en materia de interpretación de contratos internacionales para su regulación ${ }^{66}$, lo cual genera vacíos normativos para regular el contrato de franquicia internaciona $1{ }^{67}$.

Así las cosas, desde nuestra posición, una primera aproximación puede ser ofrecida desde el punto legislativo por los gobiernos de Colombia y Estados Unidos para crear puntos de conexión claros que permitan hallar la ley aplicable a los contratos de franquicia internacional. Este tipo de soluciones brinda seguridad jurídica $\mathrm{y}$ reduce los costos de transacción. En este sentido, un punto de conexión válido que podría ser introducido a las legislaciones de ambos países - emulando al establecido por la Unión Europea en el Artículo 8, Literal e) del Reglamento Roma ${ }^{68}$ - es el lugar de residencia habitual del franquiciado.

La claridad en este tema es esencial si se tiene en cuenta que en el ámbito estatal en Estados Unidos no hay total comprensión de cuál legislación resulta aplicable a contratos de franquicia en donde el franquiciado no tiene domicilio en el mencionado estado. Como consecuencia, los franquiciados colombianos pueden verse afectados por la falta de protección en Estados Unidos de sus negocios, la cual subsiste incluso si en el contrato se ha introducido una cláusula que señale como ley aplicable la ley de un estado en ese país ${ }^{69}$.

66 En este punto, hay una posible excepción a esta posición: excepción del contrato de agencia mercantil, que en el TLC Colombia-Estados Unidos se intentó regular de manera autónoma mediante la adecuación legislativa del derecho colombiano a los lineamientos establecidos en el mismo tratado.

67 La Convención de las Naciones Unidas sobre los Contratos de Compraventa Internacional de Mercaderías podría ser aplicable a cualquier contrato de compraventa que haga parte del acuerdo de franquicia. International Institute for the Unification of Private Law, UNIDROIT, Guide to International Master Franchise Arrangements (International Institute for the Unification of Private Law, UNIDROIT, Rome, 2007). Disponible en: http:/www.unidroit.org/ english/guides/2007franchising/franchising2007-guide-2nd-e.pdf

68 Unión Europea, Reglamento Roma I, Reglamento (CE) 593/2008 del Parlamento Europeo y del Consejo, de 17 de junio de 2008, sobre la ley aplicable a las obligaciones contractuales. Disponible en: http://eur-lex.europa.eu/legal-content/ES/TXT/?uri=celex:32008R0593

69 United States District Court for the Southern District of Florida, Barnes v. Burger King Corporation, 932 F. Supp. 1441 (Southern District of Florida, 1996), May 24, 1996. Disponible en: http://law.justia.com/cases/federal/district-courts/FSupp/932/1441/1398123/. United States Court for the Southern District of Florida, Burger King Corporation v. James R. Austin, Loretta W. Austin \& Austin Food Corp., 805 F. Supp. 1007 (Southern District of Florida, 1992), October 9, 1992. Disponible en: http://www.leagle.com/decision/19921812805FSupp1007_11667/ BURGER\%20KING\%20CORP.\%20v.\%20AUSTIN. United States Court for the Southern District of Florida, Burger King Corporation v. Holder, 844 F. Supp. 1528 (Southern District of Florida, 1993), February 5, 1993. Disponible en: http://law.justia.com/cases/federal/ district-courts/FSupp/844/1528/1523163/. United States District Court for the Middle District of Florida, Dickinson v. Executive Business Group, Inc., 983 F. Supp. 1395 (Middle District of 
Por otro lado, las controversias suscitadas entre las partes pueden ser solucionadas entre ellas, sin necesariamente acudir a los mecanismos de solución de controversias de carácter internacional, como el arbitraje. Para ello, los criterios de solución para los principales conflictos contractuales derivados de la ejecución del contrato de franquicia internacional en el marco del TLC Colombia-Estados Unidos deben fundamentarse en el principio de autonomía de la voluntad privada y de buena fe negocial, como pilares del derecho de comercio internacional.

Así pues, las partes contratantes - franquiciante y franquiciadodeben intentar siempre preservar la ejecución del contrato hasta su etapa final, y no quebrantar el vínculo contractual, lo cual implica: (i) la posibilidad de minimizar conflictos contractuales derivados de los vacíos normativos para la regulación del contrato mediante un código deontológico de franquicia entre Colombia y Estados Unidos que regule los principales aspectos contractuales en el proceso de negociación, ejecución y liquidación del contrato de franquicia suscrito entre un empresario colombiano y uno estadounidense, pues si bien Colombia dispone de un Código de Ética, realizado por la Cámara Colombiana de Franquicias, Colfranquicias, se considera que el mismo es insuficiente al no prever todos los aspectos mercantiles y jurídicos en que incurrirá el contrato de franquicias internacional firmado dentro del contexto del TLC suscrito entre Colombia y Estados Unidos y que se ejecutará en Colombia, y; (ii) la asunción de riesgos contractuales por las partes por medio de las denominadas cláusulas de indemnidad; y (iii) el establecimiento de cláusulas de jurisdicción y ley aplicable al contrato, que prevean las particularidades del contrato de franquicia internacional en el marco del TLC suscrito entre Colombia y Estados Unidos.

Florida, 1997), November 13, 1997. Disponible en: http://law.justia.com/cases/federal/districtcourts/FSupp/983/1395/1989291/. Al respecto, BRYAN W. DiLlon señala: "Generally, franchise acts are written to apply only to franchises located in the state or conduct occurring in the state - e.g. sales or offers to sell occurring in the state. Thus, unless there is a separate basis for application of another state's franchise laws such as the sale or offer occurred there, franchisees in one state are not ordinarily entitled to the benefit of another state's franchise laws, even if the parties expressly chose the second state's law to govern their agreement". BRYAN W. Dillon, What Law Applies? The Importance of Understanding the Interplay between Contractual Choice of Law Provisions and State Franchise Law, 14 The Franchise Lawyer, 4 (2011). Disponible en: http://www.americanbar.org/publications/franchise_lawyer/2011/fall_2011/what_ law_applies_importance_understanding_interplay_contractual_choice_law_provisions_ state_franchise_laws.html 


\section{CONCLUSIONES}

Uno de los impactos que se prevé el TLC Colombia-Estados Unidos producirá es el aumento significativo de contratos de franquicia internacional entre empresas colombianas y estadounidenses, siendo usualmente estas últimas los franquiciantes y las primeras, los franquiciados. Este aumento obedece a dos causas principales: la primera se deriva del efecto natural de los tratados de libre comercio de atraer inversión extranjera, la cual utiliza al contrato de franquicia como uno de los vehículos para traer sus modelos de negocios con el mínimo costo y riesgo. La segunda es atribuible a la adhesión de Colombia al Acuerdo de Madrid, el cual traerá como consecuencia la afluencia del registro de marcas extranjeras, muchas de ellas de compañías estadounidenses, cuyo objetivo precisamente es licenciar el uso de sus marcas, lo que arroja como resultado el aumento de contratos de franquicia.

Ahora bien, desde una perspectiva jurídica, el aumento de contratos de franquicia internacional a su vez traerá el incremento de conflictos derivados de su ejecución, lo cual obligará tanto a abogados como jueces a pensar en la solución de problemas derivados de áreas como la propiedad intelectual, derecho de la competencia, régimen tributario, conflictos de leyes y de jurisdicción, la solución de controversias, conflictos derivados de la interpretación del contrato de franquicia y sus elementos esenciales, entre otras.

Teniendo en cuenta que el contrato de franquicia es considerado en Colombia como atípico, la solución a los problemas antes mencionados puede ser incierta. Sin embargo, distintas instituciones del Estado han intentado establecer ciertos parámetros para evitar la inseguridad jurídica y el conflicto de leyes en la celebración y ejecución de los mismos. En ese sentido, la Corte Suprema de Justicia ha intentado interpretar los elementos que hacen parte del contrato de franquicia, al incluir la publicidad como parte del mismo. Igualmente, enfatizó en la importancia de la franquicia en las relaciones comerciales colombianas, al establecer la presencia de la franquicia en contratos de adhesión como el de las tarjetas de crédito.

Por otra parte, tribunales de arbitramento, adscritos al Centro de Conciliación y Arbitraje de la Cámara de Comercio de Bogotá, 
en distintos laudos han realizado una interpretación sobre la relación y coexistencia entre contratos de naturaleza similar como el de franquicia, agencia comercial, suministro y licencia; estableciendo de manera directa cuáles son los elementos de la esencia del contrato de franquicia y cómo en una relación comercial se puede evidenciar la individualización de cada uno de los contratos en virtud de la coexistencia de ellos.

Mientras tanto, en la legislación estadounidense el contrato de franquicia es un contrato regulado tanto en el ámbito estatal como en federal, en específico en torno a los deberes precontractuales de información atribuibles a los franquiciantes frente a los franquiciados y la responsabilidad derivada del incumplimiento de tales deberes. Esta situación genera un primer punto de contradicción en la regulación de ambos países en torno al contrato de franquicia, porque mientras el deber precontractual de información está regulado expresamente en esta materia en Estados Unidos, en Colombia no existe por ser el contrato de franquicia un contrato atípico. De igual forma, hay una contradicción en cuanto a los tipos de franquicia, pues en la legislación estadounidense existe la denominada franquicia de producto, la cual tiene en el régimen jurídico colombiano una naturaleza jurídica distinta, al considerarse un contrato de distribución. Así las cosas, diversos puntos de contradicción surgirán y la falta de regulación y de preparación en torno a esta figura urge la implementación de medidas legislativas para poner el país a tono con la realidad del comercio internacional. 


\section{BIBLIOGRAFÍA}

\section{Libros}

Arrubla-Paucar, Jaime Alberto, Contratos mercantiles III (Diké, Medellín, 2006).

Castro-Ruiz, Marcela; Giraldo-Bustamante, Carlos Julio; Remolina-Angarita, Nelson \& Varón-Palomino, Juan Carlos, Contratos atípicos en el derecho contemporáneo colombiano (Universidad de Los Andes, Facultad de Derecho, Cámara de Comercio de Bogotá, CCB, Fundación Universitaria Empresarial de la Cámara de Comercio de Bogotá, Uniempresarial, Bogotá, 2006).

Catoni, Jean, La rupture du contrat d'agent commercial (Sirey, Paris, 1970).

Folsom, Ralph; Wallace-Gordon, Michael \& Spanogle, John A., International Business Transactions in a Nutshell (West Academic Publishing, Saint Paul, Minnesota, 2009).

Galgano, Francesco, El negocio jurídico (Tirant lo Blanch, Valencia, 1992).

Gariazzo, Alicia, Tratados de libre comercio y desafíos competitivos para Chile: la extensión de la ISO 9000 (Serie Desarrollo Productivo, 147, Comisión Económica para América Latina y el Caribe, CEPAL, Santiago de Chile, 2004). Disponible en: http://archivo.cepal.org/pdfs/2004/S04143.pdf

Gregory, William A. \& Hurst, Thomas R., Unincorporated Business Associations (3 ed., Thomson, West Academic Publishing, Saint Paul, Minnesota, 2006).

Guardiola-Sacarrera, Enrique, La compraventa internacional: importaciones y exportaciones (Bosch, Barcelona, 2001).

Guerrero-Gaitán, Manuel, Los contratos de transferencia internacional de tecnología: América Latina, Estados Unidos y la Unión Europea (Editorial Universidad Externado de Colombia, Bogotá, 2014).

International Institute for the Unification of Private Law, UNIDROIT, Guide to International Master Franchise Arrangements (International Institute for the Unification of Private Law, UNIDROIT, Rome, 2007). Disponible en: http:// www.unidroit.org/english/guides/2007franchising/franchising2007-guide-2nd-e. pdf

KISER-Rodríguez, Luis, Franquicias, la elaboración de una idea de negocio, en base a la oportunidad detectada (Nathan Associates, Lima, Perú, 2009). Disponible en: http://www.crecemype.pe/portal/images/stories/files/FRANQUICIAS.pdf

López-GuZmán, FABIÁn, El contrato de franquicia internacional. Un modelo estratégico empresarial (Ediciones Jurídicas Gustavo Ibáñez, Bogotá, 2005).

Marzorati, Osvaldo J., Sistemas de distribución comercial (3ª ed., Astrea, Buenos Aires, 2008).

Ortega-Giménez, Alfonso, El contrato de franquicia internacional: hacia la idea global de empresa (España Exportación e Inversiones, ICEX, Madrid, 2010).

Puente-Muñoz, Teresa, El contrato de concesión mercantil (Montecorvo, Madrid, 1976).

Quintero-Delgado, Pablo José, El contrato de franquicia (Ediciones Jurídicas Gustavo 
Ibáñez, Pontificia Universidad Javeriana, Bogotá, 2012).

Superintendencia de Industria y Comercio, Propiedad industrial 2020 (Superintendencia de Industria y Comercio, Bogotá, 2012). Disponible en: http://www.sic.gov. co/recursos_user/documentos/publicaciones/Libro_PI_2020/files/libro\%20 propiedad\%20industrial\%202020.pdf, http://issuu.com/quioscosic/docs/ propiedad_industrial_2020

Vanegas-Santoro, Antonio, El contrato de franquicia (Ediciones Librería del Profesional, Bogotá, 1999).

\section{Colaboración en obras colectivas}

Insignares-Cera, Silvana, Principales conflictos contractuales derivados de la ejecución del contrato de franquicia internacional en el marco del TLC Colombia-USA, en Contrato de franquicia internacional en el marco del TLC Colombia-USA, perspectivas jurídicas y económicas, 27-59 (Silvana Insignares-Cera, ed., Universidad del Norte, ECOE Ediciones, Bogotá, 2015).

Llain-Arenilla, Shirley, El contrato de franquicia internacional: aspectos generales, en Contrato de franquicia internacional en el marco del TLC Colombia-USA, perspectivas jurídicas y económicas, 1-26 (Silvana InSIGNAREs-Cera, ed., Universidad del Norte, ECOE Ediciones, Bogotá, 2015).

Peres-Useche, Marco, Franquicias: derecho uniforme y tecnologías de información, en Derecho internacional de los negocios: alcances. Homenaje a Fernando Hinestrosa, 40 años de rectoría 1963-2003, Tomo I, 209-228 (Adriana ZAPATA DE Arbeláez, comp., Universidad Externado de Colombia, Bogotá, 2010). Disponible en: http://www.youblisher.com/p/597216-Derecho-Internacional-de-los-Negociosalcances-Tomo-I/

\section{Revistas}

Buckberg, Joel R. \& Suwanski, Jillian M., Disclosure Law Violations: Understanding the Penalties, Franchising World (agosto de 2008). Disponible en: http://www. franchise.org/Franchise-News-Detail.aspx?id=41926

Castellanos-Peñafiel, LoRena, El contrato de franquicia en el comercio internacional, 5 Foro, Revista de Derecho, 105-125 (2006). Disponible en: http://repositorio.uasb. edu.ec/bitstream/10644/1717/1/RF-05-TC-Castellanos.pdf

Dillon, Bryan W., What Law Applies? The Importance of Understanding the Interplay between Contractual Choice of Law Provisions and State Franchise Law, 14 The Franchise Lawyer, 4 (2011). Disponible en: http://www.americanbar.org/ publications/franchise_lawyer/2011/fall_2011/what_law_applies_importance_ understanding_interplay_contractual_choice_law_provisions_state_franchise_ laws.html

Londoño-Álvarez, Miguel Fernando, El contrato de franquicia internacional en Colombia, 26 Foro del Jurista, 137-146 (2005). Disponible en: http://www. camaramedellin.com.co/site/Portals/0/Documentos/Biblioteca/herramientas/ 
libro-como-exportar-en-colombia-derecho-distribucion-comercial.pdf

Metzlaff, Karsten; Issley, Norman \& Knack, Gaylen, Adapting Civil and Common Law Contracts to the U.S. Market, 10 International Journal of Franchising Law, 5, 3-29 (2012).

Mosquera-Muñoz, Felipe, La franquicia, una estrategia de crecimiento empresarial, 1 Revista MBA EAFIT, 70-85 (2010). Disponible en: http://www.eafit.edu.co/ revistas/revistamba/Documents/franquicia-estrategia-crecimiento-empresarial. pdf

Navas-Herrera, María Fernanda \& Mosquera-Moreno, Andrés Mauricio, El contrato de franquicia: aportes y tendencias en el derecho comprado sobre la responsabilidad el franquiciador, 119 Revista Vniversitas, 279-304 (2009). Disponible en: http:// www.scielo.org.co/pdf/vniv/n119/n119a17.pdf

Pengilley, Warren, International Franchising Arrangements and Problems in their Negotiation, 7 Northwestern Journal International Law \& Business, 2, 185-207 (1985). Disponible en: http://scholarlycommons.law.northwestern.edu/cgi/ viewcontent.cgi?article $=1196 \&$ context $=$ njilb

Plazas-Estepa, Rodrigo Alberto, El know-how dentro de los contratos de franquicia en Colombia, 10 Revista Republicana, 67-79 (2011). Disponible en: http://revista.urepublicana.edu.co/wp-content/uploads/2012/07/E1know $\%$ E2\%80\%93howdentro-de-los-contratos-de-franquicia-en-Colombia.pdf

Schachner-Chanen, Jill, Growing Pains for Franchise Law, American Bar Association Journal (April 2006).

\section{Tratados internacionales}

Chile \& Estados Unidos, Tratado de Libre Comercio, vigente desde el 1 de enero de 2004. Disponible en: http://www.wipo.int/edocs/lexdocs/treaties/es/cl-us/trt_cl_us.pdf

Colombia \& Estados Unidos, Tratado de Libre Comercio (TLC), vigente desde el 15 de mayo de 2012. Disponible en: http://www.tlc.gov.co/publicaciones.php?id=727

Comunidad Andina, Decisión 486, Régimen Común sobre Propiedad Industrial, 14 de septiembre de 2000. Disponible en: http://www.wipo.int/wipolex/es/text. jsp?file_id=223651

Instituto Internacional para la Unificación del Derecho Privado, UNIDROIT, Ley Modelo sobre la divulgación de la información en materia de franquicia, Roma, 2004. Disponible en: http://www.unidroit.org/spanish/ modellaws/2002franchise/2002modellaw-s.PDF

Organización Internacional de Propiedad Intelectual, OMPI, Protocolo concerniente al Arreglo de Madrid relativo al Registro Internacional de Marcas, adoptado en 1891, revisado en Bruselas (1900), en Washington (1911), en La Haya (1925), en Londres (1934), en Niza (1957) y en Estocolmo (1967), y enmendado en 1979; y el Protocolo concerniente a ese Arreglo, adoptado en 1989. Disponible en: http:// www.wipo.int/export/sites/www/madrid/es/legal_texts/pdf/madrid_protocol. pdf, http://www.wipo.int/treaties/es/registration/madrid_protocol/

Perú \& Estados Unidos, Tratado de Libre Comercio (TLC), vigente desde el 1 de 
febrero de 2009. Disponible en: http://www.acuerdoscomerciales.gob.pe/index. php?option=com_content $\&$ view $=$ category\&layout $=$ blog\&id $=57 \&$ Itemid $=80$

Organización de las Naciones Unidas, ONU, Convención de las Naciones Unidas sobre los Contratos de Compraventa Internacional de Mercaderías de 1980 (Organización de las Naciones Unidas, Nueva York, 2011). Disponible en: https:// www.uncitral.org/pdf/spanish/texts/sales/cisg/V1057000-CISG-s.pdf

Unión Europea, Reglamento Roma I, Reglamento (CE) 593/2008 del Parlamento Europeo y del Consejo, de 17 de junio de 2008, sobre la ley aplicable a las obligaciones contractuales. Disponible en: http://eur-lex.europa.eu/legal-content/ ES/TXT/?uri=celex:32008R0593

\section{Normatividad internacional}

Asociación Europea de Franquicias, Código Deontológico, 1 de enero de 1991. Disponible en: http://www.guia.ceei.es/archivos/Documento/Codigo_ Deontologico_Europeo_franquicia.pdf

Estados Unidos, Code of Federal Regulations, CFR. Disponible en: https://www.gpo. gov/fdsys/browse/collectionCfraction?collectionCode $=$ CFR

Estados Unidos, Federal Trade Commission, Rule on Disclosure Requirements and Prohibitions Concerning Franchising and Business Opportunity Ventures. Disponible en: https://www.ftc.gov/policy/federal-register-notices/disclosurerequirements-and-prohibitions-concerning-franchising

Estados Unidos, Federal Trade Commission Act, 15 U.S.C. $\S \S 41-58$, as amended. Disponible en: https://www.ftc.gov/es/enforcement/statutes/federal-tradecommission-act

Estados Unidos, New York General Business Law. Disponible en: http://codes.findlaw. com/ny/general-business-law/

Estados Unidos, Restatement of Law - Agency. Disponible en: https://users. wfu.edu/palmitar/ICBCorporations-Companion/Conexus/UniformActs/ Restatement(third)Agency.pdf

Estados Unidos, California, Franchise Investment Law del Estado de California. Disponible en: http://www.dbo.ca.gov/Licensees/franchise_investment_law/

Estados Unidos, Hawaii, Franchise Investment Law del Estado de Hawaii. Disponible en: http://codes.lp.findlaw.com/histatutes/2/26/482E

Estados Unidos, Illinois, Franchise Disclosure Act of 1987. http://www.ilga.gov/ legislation/ilcs/ilcs3.asp?ActID=2381

Estados Unidos, New York, Franchise Investment Law, Ley de Franquicia del Estado de Nueva York. Disponible en: https://www.ag.ny.gov/sites/default/files/pdfs/ bureaus/investor_protection/franchise/part200.pdf 


\section{Normatividad colombiana}

Cámara Colombiana de Franquicias, Código de Ética para las Franquicias, 4 de diciembre de 2012. Disponible en: http://www.colfranquicias.com/la-asociacion/ codigo-de-etica.html

Colombia, Decreto 410 de 1971, por el cual se expide el Código de Comercio, 33.339 Diario Oficial, 16 de junio de 1971. Disponible en: http://www.secretariasenado. gov.co/senado/basedoc/codigo_comercio.html

Colombia, Decreto 3523 de 2009, por el cual se modifica la estructura de la Superintendencia de Industria y Comercio y se determinan las funciones de sus dependencias, 47.473 Diario Oficial, 15 de septiembre de 2009. Disponible en: https://www.cancilleria.gov.co/sites/default/files/Normograma/docs/ decreto_3523_2009.htm

Colombia, Decreto 1687 de 2010, por el cual se modifica el Decreto 3523 de 2009, 47.709 Diario Oficial, 14 de mayo de 2010. Disponible en: http://www.secretariasenado. gov.co/senado/basedoc/decreto_1687_2010.html

Colombia, Ley 1455 de 2011, por medio de la cual se aprueba el Protocolo concerniente al arreglo de Madrid relativo al Registro Internacional de Marcas, adoptado en Madrid el 27 de junio de 1989, modificado el 3 de octubre de 2006 y el 12 de noviembre de 2007, 48.116 Diario Oficial, 30 de junio de 2011. Disponible en: http://www.secretariasenado.gov.co/senado/basedoc/ley_1455_2011.html

Colombia, Ley 1480 de 2011, por medio de la cual se expide el Estatuto del Consumidor y se dictan otras disposiciones, 48.220 Diario Oficial, 12 de octubre de 2011. Disponible en: http://www.secretariasenado.gov.co/senado/basedoc/ ley_1480_2011.html

Instituto Colombiano de Normas Técnicas y Certificación, ICONTEC, Norma técnica colombiana NTC 5813. Franquicias. Requisitos generales para la etapa precontractual, contractual y postcontractual de una franquicia, en Servicios, organización y gestión de la empresa. Administración y organización de empresas. Transporte (Instituto Colombiano de Normas Técnicas y Certificación, ICONTEC, Bogotá, 2010).

\section{Jurisprudencia colombiana}

Centro de Arbitramento de la Cámara de Comercio de Bogotá, Supercar Ltda. vs. Sociedad de Fabricación de Automotores S.A., Sofasa, laudo arbitral de 31 de marzo de 1998.

Centro de Arbitramento de la Cámara de Comercio de Bogotá, División Mayor del Fútbol Colombiano, Dimayor vs. Radio Cadena Nacional S.A., RCN y Caracol Televisión S.A., laudo arbitral de 6 de junio de 2001.

Centro de Arbitramento de la Cámara de Comercio de Bogotá, Gallo's Comunicaciones E.U. vs. Super 9 Comunicaciones S. A., laudo arbitral de 17 de noviembre de 2004.

Centro de Arbitramento de la Cámara de Comercio de Bogotá, Telemóvil Colombia S.A. vs. Colombia Móvil S.A. ESP, laudo arbitral de 3 de mayo de 2007. 
Centro de Arbitramento de la Cámara de Comercio de Bogotá, Chevron Petroleum Company vs. Mariana Fandiño de Rubio y Carlos Guillermo Rubio-Fandiño, laudo arbitral de 16 de septiembre de 2008.

Centro de Arbitramento de la Cámara de Comercio de Bogotá, Tribunal de arbitramento ad-hoc, Megaenlace Net S.A., vs. Telefónica Móviles de Colombia S.A., laudo arbitral de 25 de marzo de 2009.

Corte Suprema de Justicia, Sala de Casación Civil y Agraria, sentencia del 12 de septiembre de 1995, expediente 3939, magistrado ponente Nicolás BecharaSimancas. Disponible en: http://www.notinet.com.co/pedidos/3939.doc

Corte Suprema de Justicia, Sala de Casación Civil y Agraria, sentencia del 8 de agosto de 2001, expediente 5905, magistrado ponente Jorge Antonio Castillo-Rugeles.

Superintendencia de Industria y Comercio, Circular Única, 18 de julio de 2001. Disponible en: http://www.sic.gov.co/drupal/titulos-circular-unica

Superintendencia de Industria y Comercio, Concepto 133956, 28 de octubre de 2011.

Superintendencia de Industria y Comercio, Concepto 1212079400000000, 18 de julio de 2012.

Superintendencia de Industria y Comercio, Concepto 13-095-570, 28 de mayo de 2013.

\section{Casos}

United States Court for the Southern District of Florida, Burger King Corporation v. James R. Austin, Loretta W. Austin \& Austin Food Corp., 805 F. Supp. 1007 (Southern District of Florida, 1992), October 9, 1992. Disponible en: http://www. leagle.com/decision/19921812805FSupp1007_11667/BURGER $\% 20$ KING\%20 CORP.\%20v.\%20AUSTIN

United States Court for the Southern District of Florida, Burger King Corporation v. Holder, 844 F. Supp. 1528 (Southern District of Florida, 1993), February

5, 1993. Disponible en: http://law.justia.com/cases/federal/district-courts/ FSupp/844/1528/1523163/

United States District Court for the Eastern District of Missouri, Joseph James, Darrell Woods and Saint Louis Appliance Parts Inc. v. Whirlpool Corp., 806 F. Supp. 835 (Eastern District Missouri 1992), October 26, 1992. Disponible en: http://law. justia.com/cases/federal/district-courts/FSupp/806/835/1747761/

United States District Court for the Middle District of Florida, Dickinson v. Executive Business Group, Inc., 983 F. Supp. 1395 (Middle District of Florida, 1997), November 13, 1997. Disponible en: http://law.justia.com/cases/federal/districtcourts/FSupp/983/1395/1989291/

United States District Court for the Southern District of Florida, Barnes v. Burger King Corporation, 932 F. Supp. 1441 (Southern District of Florida, 1996), May 24, 1996. Disponible en: http://law.justia.com/cases/federal/district-courts/ FSupp/932/1441/1398123/ 


\section{Medios de comunicación, direcciones web}

El Heraldo, Avanza TLC: empresarios de EU ofrecen franquicias en Colombia, El Heraldo, Economía, Barranquilla (14 de febrero de 2013). Disponible en: http:// www.elheraldo.co/noticias/economia/avanza-tlc-empresarios-de-eu-ofrecenfranquicias-en-colombia-100109

Herrera-Mora, Camilo, ¿Nuestras marcas están listas para el TLC con Estados Unidos?, Diario La República (13 de marzo de 2013). Disponible en: http://www. larepublica.co $\% \mathrm{C} 2 \% \mathrm{BFnuestras-marcas-est} \% \mathrm{C} 3 \% \mathrm{~A} 1 n$-listas-para-el-tlc-conestados-unidos_4145

US Embassy Bogotá (19 de julio de 2012). FTA also Opens Up Opportunities in Franchising. Disponible en: http://usbusiness-opportunities-embassybogota.com/2012/07/19/ fta-also-opens-up-opportunities-in-franchising/ 
